\title{
Respiratory Mechanics in Mechanically Ventilated Patients
}

\author{
Dean R Hess PhD RRT FAARC
}

\author{
Introduction \\ Pressure \\ Airway Pressure \\ Equation of Motion \\ Alveolar Pressure \\ Plateau Pressure \\ Auto-PEEP \\ Mean Airway Pressure \\ Esophageal Pressure \\ Transpulmonary Pressure \\ Intra-Abdominal Pressure \\ Transdiaphragmatic Pressure \\ Asynchrony \\ Stress Index \\ Flow and Volume \\ Time Constant \\ Inspiratory Flow \\ Expiratory Flow \\ Tidal Volume \\ End-Expiratory Lung Volume \\ Derived Measurements \\ Respiratory System Compliance \\ Chest-Wall Compliance \\ Lung Compliance \\ Airway Resistance \\ Work of Breathing \\ Pressure-Volume Curves \\ Flow-Volume Loops \\ Tension-Time Index and Pressure-Time Product \\ Esophageal Pressure for PEEP Titration \\ Stress and Strain \\ Spontaneous Breathing and Pressure-Targeted Ventilation \\ Pleural Pressure and Hemodynamics During Mechanical Ventilation
}

Respiratory mechanics refers to the expression of lung function through measures of pressure and flow. From these measurements, a variety of derived indices can be determined, such as volume, compliance, resistance, and work of breathing. Plateau pressure is a measure of end-inspiratory distending pressure. It has become increasingly appreciated that end-inspiratory transpulmonary pressure (stress) might be a better indicator of the potential for lung injury than plateau pressure alone. This has resulted in a resurgence of interest in the use of esophageal manometry in mechanically ventilated patients. End-expiratory transpulmonary pressure might also be useful to guide the 
setting of PEEP to counterbalance the collapsing effects of the chest wall. The shape of the pressuretime curve might also be useful to guide the setting of PEEP (stress index). This has focused interest in the roles of stress and strain to assess the potential for lung injury during mechanical ventilation. This paper covers both basic and advanced respiratory mechanics during mechanical ventilation. Key words: auto-PEEP; chest wall; compliance; esophageal pressure; mechanical ventilation; plateau pressure; resistance; respiratory mechanics; work of breathing. [Respir Care 2014;59(11):1773-1794. (C) 2014 Daedalus Enterprises]

\section{Introduction}

Respiratory mechanics refers to the expression of lung function through measures of pressure and flow. ${ }^{1,2}$ From these measurements, a variety of derived indices can be determined, such as volume, compliance, resistance, and work of breathing (WOB). Waveforms are derived when one of the parameters of respiratory mechanics is plotted as a function of time or as a function of one of the other parameters. This produces scalar tracings of pressuretime, flow-time, and volume-time graphics, as well as flow-volume and pressure-volume (P-V) loops. All currentgeneration positive-pressure ventilators provide some monitoring of pulmonary mechanics and graphics in real time at the bedside. When interpreting these measurements, it is important to remember that bedside monitoring of mechanics and graphics during positive-pressure ventilation portrays the lungs as a single compartment and assumes a linear response over the range of tidal volume $\left(\mathrm{V}_{\mathrm{T}}\right)$. Although this is a physiologic oversimplification, the information nonetheless is useful to evaluate lung function, assess response to therapy, and optimize mechanical ventilator support. An evaluation of respiratory mechanics allows the best available evidence to be individualized to the patient. By necessity, any discussion of respiratory mechanics involves mathematics. Fortunately, much of the mathematics is basic algebra, and for the most part, I will stick to that in this paper.

Dr Hess is affiliated with Respiratory Care Services, Massachusetts General Hospital, and Harvard Medical School, Boston, Massachusetts.

Dr Hess discloses relationships with Philips Respironics, Pari, Covidien, Maquet, Merck, Bayer, McGraw-Hill, Jones and Bartlett, and UpToDate.

Dr Hess presented a version of this paper at the 29th New Horizons in Respiratory Care Symposium: Back to the Basics: Respiratory Physiology in Critically Ill Patients at the 59th AARC Congress, held November 16-19, 2013, in Anaheim, California.

Correspondence: Dean R Hess PhD RRT FAARC, Respiratory Care Services, Ellison 401, Massachusetts General Hospital, 55 Fruit Street, Boston, MA 02114. E-mail: dhess@ partners.org.

DOI: $10.4187 /$ respcare. 03410

\section{Pressure}

\section{Airway Pressure}

Airway pressure is measured universally during mechanical ventilation. Pressure is measured ideally at the proximal airway, but most ventilators do not because proximal airway pressure monitoring exposes the sensor to secretions and carries other technical issues. ${ }^{3}$ Alternatively, the ventilator can measure pressure proximal to the expiratory valve during the inspiratory phase to approximate inspiratory proximal airway pressure, and it can measure pressure distal to the inspiratory valve during the expiratory phase to approximate expiratory proximal airway pressure. Because flow in the expiratory limb is zero during the inspiratory phase and flow in the inspiratory limb is zero during the expiratory phase, pressures measured in this manner should approximate proximal airway pressure.

Airway pressure is typically displayed on the ventilator screen as a function of time. The shape of the airway pressure waveform is determined by flow and $V_{T}$ from the ventilator, lung mechanics, and any active breathing efforts of the patient.

\section{Equation of Motion}

Airway pressure is predicted mathematically by the equation of motion:

$$
\begin{aligned}
\mathrm{P}_{\text {vent }}+\mathrm{P}_{\mathrm{mus}}=\mathrm{V}_{\mathrm{T}} / \mathrm{C}_{\mathrm{RS}} & +\mathrm{R}_{\mathrm{aw}} \times \dot{\mathrm{V}}_{\mathrm{I}} \\
& + \text { PEEP }+ \text { PEEPi }+ \text { inertance }
\end{aligned}
$$

where $\mathrm{P}_{\mathrm{vent}}$ is the proximal airway pressure applied by the ventilator, $\mathrm{P}_{\mathrm{mus}}$ is the pressure generated by the patient's inspiratory muscles, $\mathrm{V}_{\mathrm{T}}$ is tidal volume, $\mathrm{C}_{\mathrm{RS}}$ is respiratory system compliance, $R_{a w}$ is airway resistance, $\dot{V}_{I}$ is inspiratory flow, PEEP is the PEEP set on the ventilator, and PEEPi is intrinsic PEEP (auto-PEEP). The inertance variable, representing the effect of inertia, is assumed to be low and thus disregarded.

$R_{a w}$ and $C_{R S}$ can be obtained by fitting the equation of motion to $\mathrm{P}, \mathrm{V}$, and $\dot{\mathrm{V}}$ with a multiple linear regression analysis, called linear least-squares fitting. ${ }^{4}$ This approach 
is incorporated into the software of some ventilators, allowing display of $\mathrm{R}_{\mathrm{aw}}, \mathrm{C}_{\mathrm{RS}}$, and auto-PEEP without the need for inspiratory and expiratory pause maneuvers. $\mathrm{P}, \mathrm{V}$, and $\dot{V}$ are digitized at $100 \mathrm{~Hz}$, allowing $\mathrm{R}_{\mathrm{aw}}$ and $\mathrm{C}_{\mathrm{RS}}$ be calculated from 100 or more equations per breath. This method can be applied during the whole breathing cycle or only in the inspiratory or expiratory phase, although restricting the analysis to the inspiratory phase may be more appropriate in patients with COPD who have flow limitation. The least-squares fitting method assumes that $\mathrm{P}_{\text {mus }}$ is zero and is thus less valid if the patient is actively breathing. An important methodological issue is that the leastsquares fitting approach uses a single linear model that does not take into account changes of $R_{a w}$ and $C_{R S}$ with lung volume, and it also neglects flow turbulence and inertial forces.

\section{Alveolar Pressure}

During volume control ventilation, alveolar pressure $\left(\mathrm{P}_{\text {alv }}\right)$ at any time during inspiration is determined by the volume delivered and $C_{R S}: P_{a l v}=V / C_{R S}+$ PEEP. For pressure control ventilation, $\mathrm{P}_{\text {alv }}$ at any time after the initiation of inspiration is: $\mathrm{P}_{\mathrm{alv}}=\Delta \mathrm{P} \times\left(1-\mathrm{e}^{-\mathrm{t} / \tau}\right)+\mathrm{PEEP}$, where $\Delta \mathrm{P}$ is the pressure applied to the airway above PEEP, $e$ is the base of the natural logarithm, $t$ is the elapsed time after initiation of the inspiratory phase, and $\tau$ is the time constant.

\section{Plateau Pressure}

Due to $R_{a w}$, proximal airway pressure will always be greater than $\mathrm{P}_{\mathrm{alv}}$ during inspiration if flow is present. $\mathrm{P}_{\mathrm{alv}}$ is estimated with an end-inspiratory hold maneuver. Plateau pressure $\left(\mathrm{P}_{\text {plat }}\right)$ is measured during mechanical ventilation by applying an end-inspiratory breath-hold for $0.5-2 \mathrm{~s}$, during which pressure equilibrates throughout the system, so the pressure measured at the proximal airway approximates the $\mathrm{P}_{\text {alv }}$ (Fig. 1).

With rapid airway occlusion at the end of inspiration, flow drops to zero, and the proximal airway pressure immediately decreases to a lower level (the pressure at zero flow $\left.\left[\mathrm{P}_{\mathrm{z}}\right]\right) . \mathrm{R}_{\mathrm{aw}}$ and end-inspiratory flow determine the difference between peak inspiratory pressure (PIP) and $\mathrm{P}_{\mathrm{z}}$. During airway occlusion, pressure further declines to reach a plateau $\left(\mathrm{P}_{\text {plat }}\right)$. The difference between $\mathrm{P}_{\mathrm{z}}$ and $\mathrm{P}_{\text {plat }}$ is determined by time constant heterogeneity within the lungs (ie, pendelluft) and the viscoelastic behavior of the stress relaxation of the pulmonary tissues. Measurement of $\mathrm{P}_{\text {plat }}$ is valid only during passive inflation of the lungs, but not during active breathing. During pressure control ventilation, the flow might decrease to zero at the end of the inspiratory phase; if this occurs, PIP and $\mathrm{P}_{\text {plat }}$ are equal.

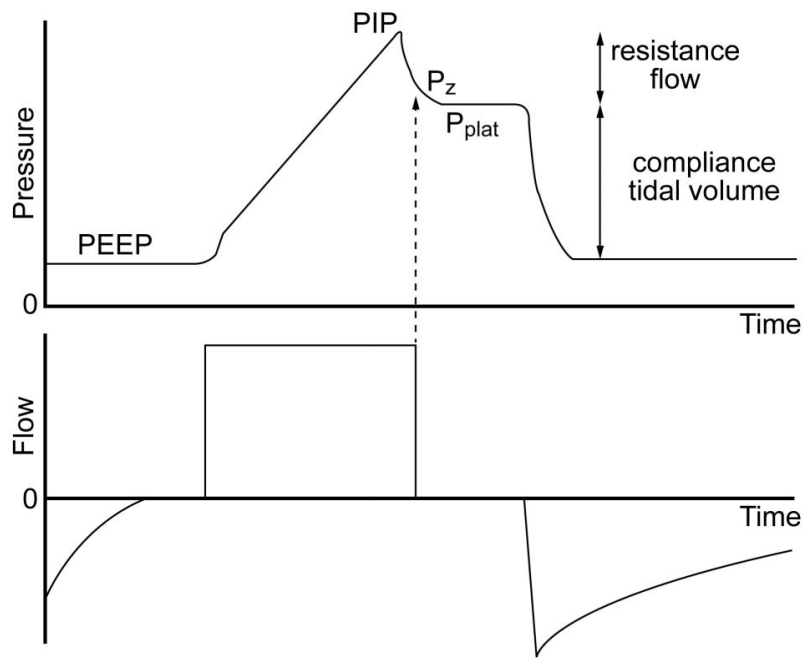

Fig. 1. Airway pressure and flow waveforms during constant flow volume control ventilation, illustrating the effect of an endinspiratory breath-hold. With a period of no flow, the pressure equilibrates to the plateau pressure $\left(P_{\text {plat }}\right)$. $P_{\text {plat }}$ represents the peak alveolar pressure. The difference between $P_{z}$ and $P_{\text {plat }}$ is due to time constant inhomogeneity within the lungs. The difference between the peak inspiratory pressure (PIP) and $P_{\text {plat }}$ is determined by resistance and flow. The difference between $P_{\text {plat }}$ and PEEP is determined by tidal volume and respiratory system compliance. $P_{z}=$ pressure at zero flow.

$\mathrm{P}_{\text {plat }}$ is determined by $\mathrm{V}_{T}$ and $\mathrm{C}_{\mathrm{RS}}$ during full ventilatory support: $\mathrm{P}_{\text {plat }}=\mathrm{V}_{\mathrm{T}} / \mathrm{C}_{\mathrm{RS}}$. A high $\mathrm{P}_{\text {plat }}$ indicates risk of alveolar over-distention. $\mathrm{P}_{\text {plat }}$ should ideally be kept at $\leq 30 \mathrm{~cm} \mathrm{H}{ }_{2} \mathrm{O},{ }^{5}$ with some evidence suggesting that $\mathrm{P}_{\text {plat }}$ should be targeted to $<25 \mathrm{~cm} \mathrm{H}_{2} \mathrm{O}$ in patients with ARDS. ${ }^{6,7}$ This assumes that chest-wall compliance $\left(\mathrm{C}_{\mathrm{CW}}\right)$ is normal. A high $\mathrm{P}_{\text {plat }}$ may be safe (and necessary) if $\mathrm{C}_{\mathrm{CW}}$ is decreased.

A method has been described that uses the expiratory time constant $\left(\tau_{\mathrm{E}}\right)$ to provide real-time determinations of $\mathrm{P}_{\text {plat }}$ without the need for an end-inspiratory pause maneuver. ${ }^{8}$ Using this approach, $\tau_{\mathrm{E}}$ is estimated from the slope of the passive expiratory flow curve between 0.1 and $0.5 \mathrm{~s}$. $\mathrm{P}_{\text {plat }}$ is then calculated as:

$$
\mathrm{P}_{\text {plat }}=\frac{\left(\mathrm{V}_{\mathrm{T}} \times \mathrm{PIP}\right)-\left(\mathrm{V}_{\mathrm{T}} \times \text { PEEP }\right)}{\mathrm{V}_{\mathrm{T}}+\left(\tau_{\mathrm{E}} \times \dot{\mathrm{V}}_{\mathrm{I}}\right)}
$$

This approach has the advantage of being able to be used in spontaneous breathing modes such as pressure support, but has the disadvantage of requiring a computerized algorithm to make the necessary calculations.

\section{Auto-PEEP}

Incomplete emptying of the lungs occurs if the expiratory phase is terminated prematurely. The pressure 


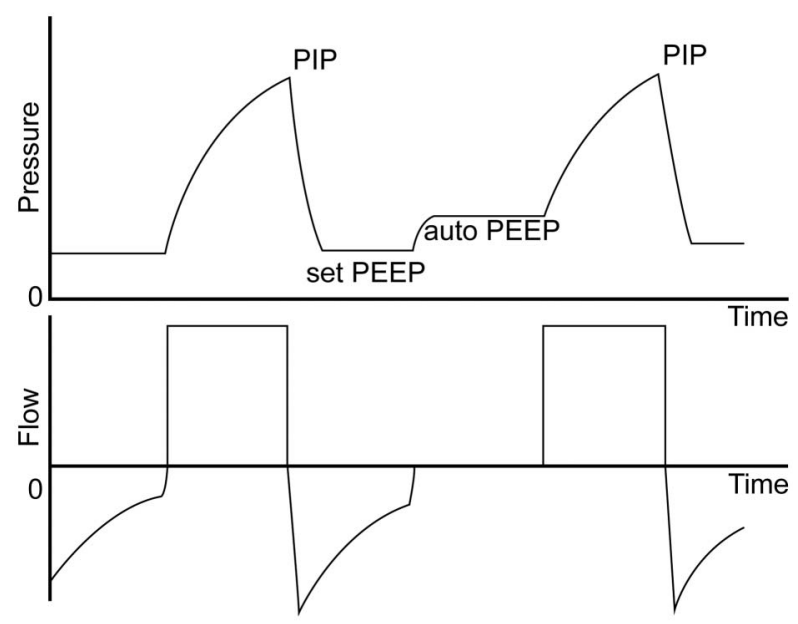

Fig. 2. Applying an end-expiratory breath-hold allows measurement of end-expiratory alveolar pressure. The difference between PEEP set and the pressure measured during this maneuver is the amount of auto-PEEP. PIP = peak inspiratory pressure.

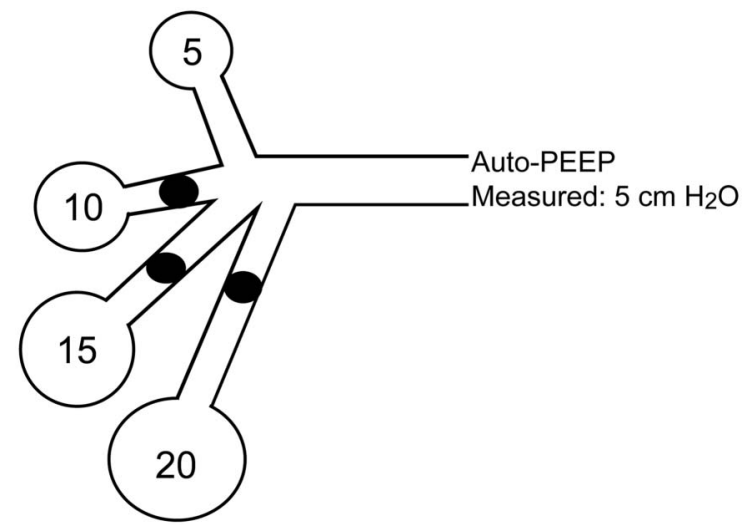

Fig. 3. As illustrated here, the measured auto-PEEP can be considerably less than the auto-PEEP in some lung regions if airways collapse during exhalation.

produced by this trapped gas is called auto-PEEP, intrinsic PEEP, or occult PEEP. Auto-PEEP increases endexpiratory lung volume and thus causes dynamic hyperinflation. ${ }^{9,10}$

Auto-PEEP is measured by applying an end-expiratory pause for $0.5-2 \mathrm{~s}$ (Fig. 2). The pressure measured at the end of this maneuver in excess of the PEEP set on the ventilator is defined as auto-PEEP. For a valid measurement, the patient must be relaxed and breathing in synchrony with the ventilator, as active breathing invalidates the measurement. The end-expiratory pause method can underestimate auto-PEEP when some airways close during exhalation, as may occur during ventilation of the lungs of patients with severe asthma (Fig. 3). In spontaneously breathing patients, measurement of esophageal pressure $\left(\mathrm{P}_{\mathrm{es}}\right)$ can be used to determine auto-PEEP (Fig. 4).
Auto-PEEP is a function of ventilator settings $\left(\mathrm{V}_{\mathrm{T}}\right.$ and expiratory time $\left.\left[\mathrm{T}_{\mathrm{E}}\right]\right)$ and lung function $\left(\mathrm{R}_{\mathrm{aw}}\right.$ and lung compliance $\left.\left[\mathrm{C}_{\mathrm{L}}\right]\right)$ : auto-PEEP $=\mathrm{V}_{\mathrm{T}} /\left(\mathrm{C}_{\mathrm{RS}} \times\left(\mathrm{e}^{\mathrm{Kx} \times \mathrm{T}_{\mathrm{E}}-1}\right)\right.$, where $\mathrm{Kx}$ is the inverse of the $\tau_{\mathrm{E}}(1 / \tau)$. Note that autoPEEP is increased with increased resistance and compliance, increased breathing frequency or increased inspiratory time $\left(\mathrm{T}_{\mathrm{I}}\right.$; both decrease $\mathrm{T}_{\mathrm{E}}$ ), and increased $\mathrm{V}_{\mathrm{T}}$. Clinically, auto-PEEP can be decreased by decreasing minute ventilation (rate or $\mathrm{V}_{\mathrm{T}}$ ), increasing $\mathrm{T}_{\mathrm{E}}$ (decreasing rate or $\mathrm{T}_{\mathrm{I}}$ ), or decreasing $\mathrm{R}_{\mathrm{aw}}$ (eg, bronchodilator administration).

\section{Mean Airway Pressure}

Mean airway pressure $\left(\overline{\mathrm{P}}_{\mathrm{aw}}\right)$ is determined by PIP, the fraction of time devoted to the inspiratory phase $\left(\mathrm{T}_{\mathrm{I}} / \mathrm{T}_{\text {tot }}\right.$, where $T_{\text {tot }}$ is total respiratory cycle time), and PEEP. For constant flow-volume ventilation, in which the airway pressure waveform is triangular, $\overline{\mathrm{P}}_{\mathrm{aw}}$ can be calculated as: $\overline{\mathrm{P}}_{\mathrm{aw}}=0.5 \times(\mathrm{PIP}-\mathrm{PEEP}) \times\left(\mathrm{T}_{\mathrm{I}} / \mathrm{T}_{\mathrm{tot}}\right)+$ PEEP. During pressure ventilation, in which the airway pressure waveform is rectangular, $\overline{\mathrm{P}}_{\mathrm{aw}}$ can be estimated as: $\overline{\mathrm{P}}_{\mathrm{aw}}=(\mathrm{PIP}$ - PEEP) $\times\left(\mathrm{T}_{\mathrm{I}} / \mathrm{T}_{\text {tot }}\right)+$ PEEP. The mean $\mathrm{P}_{\text {alv }}$ may be different than $\overline{\mathrm{P}}_{\mathrm{aw}}$ if the inspiratory airway resistance $\left(\mathrm{R}_{\mathrm{I}}\right)$ and expiratory airway resistance $\left(\mathrm{R}_{\mathrm{E}}\right)$ are different, which is often the case in lung disease: mean $\mathrm{P}_{\mathrm{alv}}=\overline{\mathrm{P}}_{\mathrm{aw}}+$ $\left(\dot{\mathrm{V}}_{\mathrm{E}} / 60\right) \times\left(\mathrm{R}_{\mathrm{E}}-\mathrm{R}_{\mathrm{I}}\right)$, where $\dot{\mathrm{V}}_{\mathrm{E}}$ is expiratory flow.

\section{Esophageal Pressure}

Pleural pressure $\left(\mathrm{P}_{\mathrm{pl}}\right)$ cannot be easily measured directly. The traditional approach to assess $\mathrm{P}_{\mathrm{pl}}$ is the use of an esophageal balloon, ${ }^{11-18}$ which consists of a thin catheter with multiple small holes in the distal 5-7 cm of its length. A 10-cm-long balloon is placed over the distal end of the catheter to prevent the holes in the catheter from being occluded by esophageal tissue and secretions, and the balloon is inflated with a small amount of air $(0.5 \mathrm{~mL})$. The proximal end of the catheter is attached to a pressure transducer.

The catheter is inserted orally or nasally to $\sim 35-40 \mathrm{~cm}$ from the airway opening. Correct positioning of the esophageal balloon is necessary to ensure accurate $P_{\text {es }}$ measurements. After the balloon is inflated and the pressure is measured, the $\mathrm{P}_{\mathrm{es}}$ waveform should be compared to the airway pressure waveform. If they appear similar in pressure and shape, the catheter is likely in the trachea and should be removed. If the catheter is in the esophagus, cardiac oscillations should be visible on the $\mathrm{P}_{\mathrm{es}}$ waveform, indicating that the balloon is positioned in the lower third of the esophagus directly behind the heart (Fig. 5). 

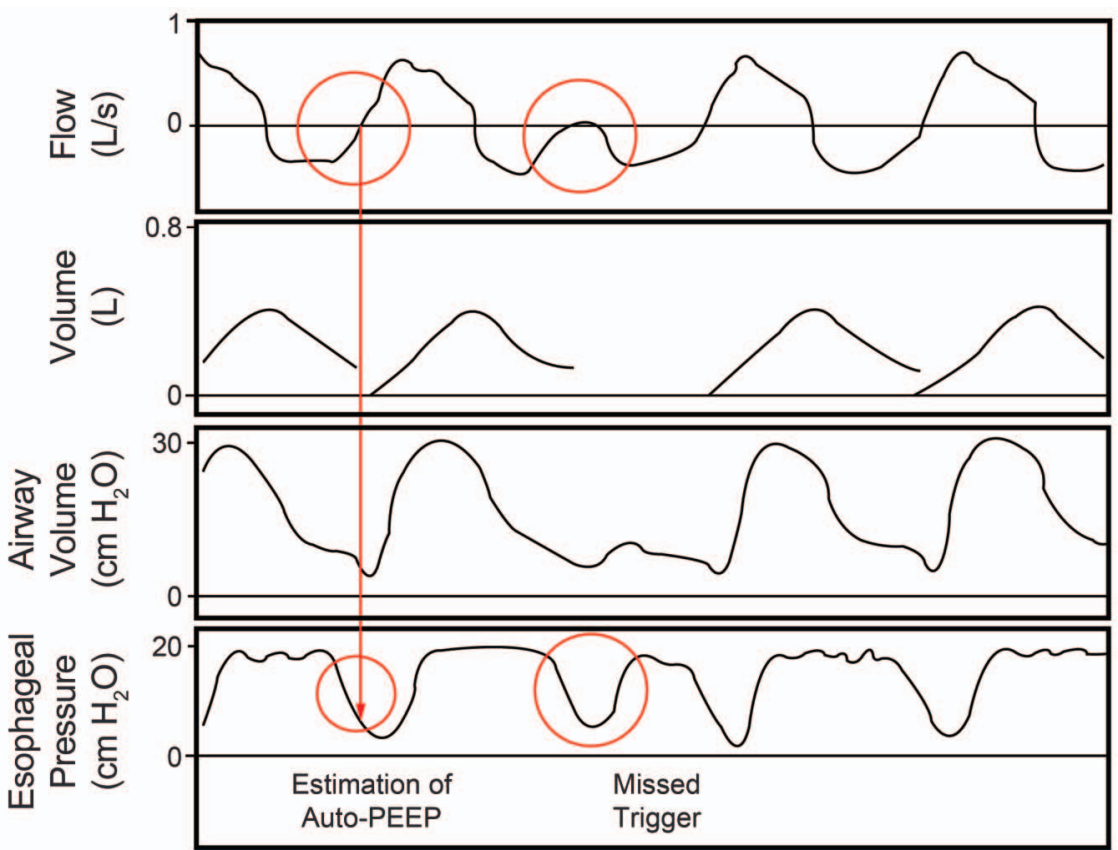

Fig. 4. Airway pressure, flow, volume, and esophageal pressure $\left(P_{\text {es }}\right)$ waveforms in a patient with auto-PEEP. Note the decrease in $P_{\text {es }}$ required to trigger the ventilator, which represents the amount of auto-PEEP. Also note that flow does not return to zero at the end of exhalation, and the inspiratory effort does not trigger the ventilator.
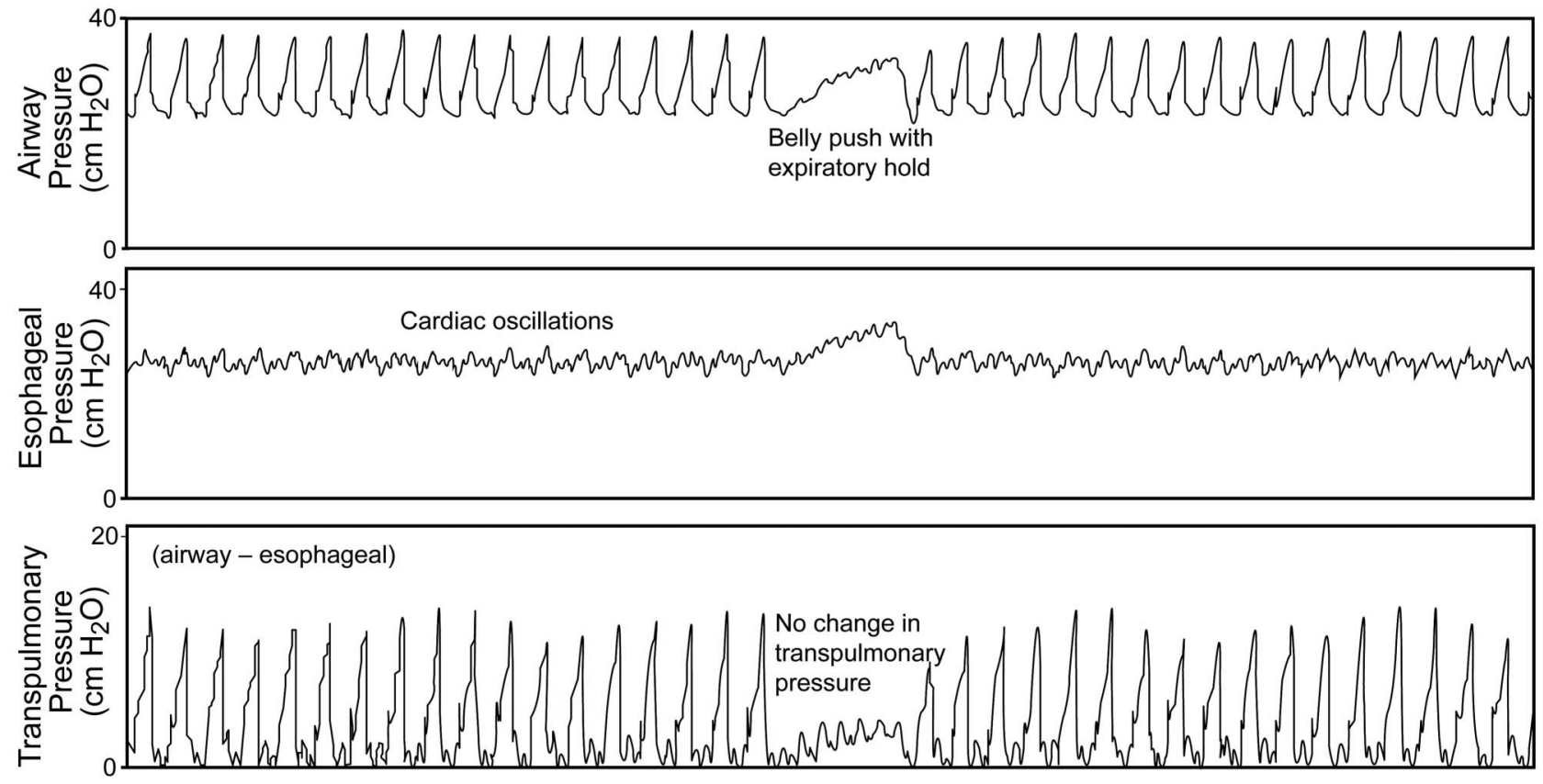

Fig. 5. Illustrated here are several features used to determine that the esophageal balloon is correctly placed in the esophagus. Notice the presence of cardiac oscillations on the esophageal pressure waveform. Also note that there is no change in transpulmonary pressure when pressure is applied to the abdomen.

Some clinicians use a technique in which the catheter is intentionally inserted into the stomach, air is added to the balloon, and the catheter is then withdrawn until cardiac oscillations are observed.
The classic technique used to validate the balloon's position requires the patient to perform static Valsalva and Müller maneuvers with the glottis open. In patients unable to cooperate, changes in $\mathrm{P}_{\mathrm{es}}$ and airway pressure are as- 

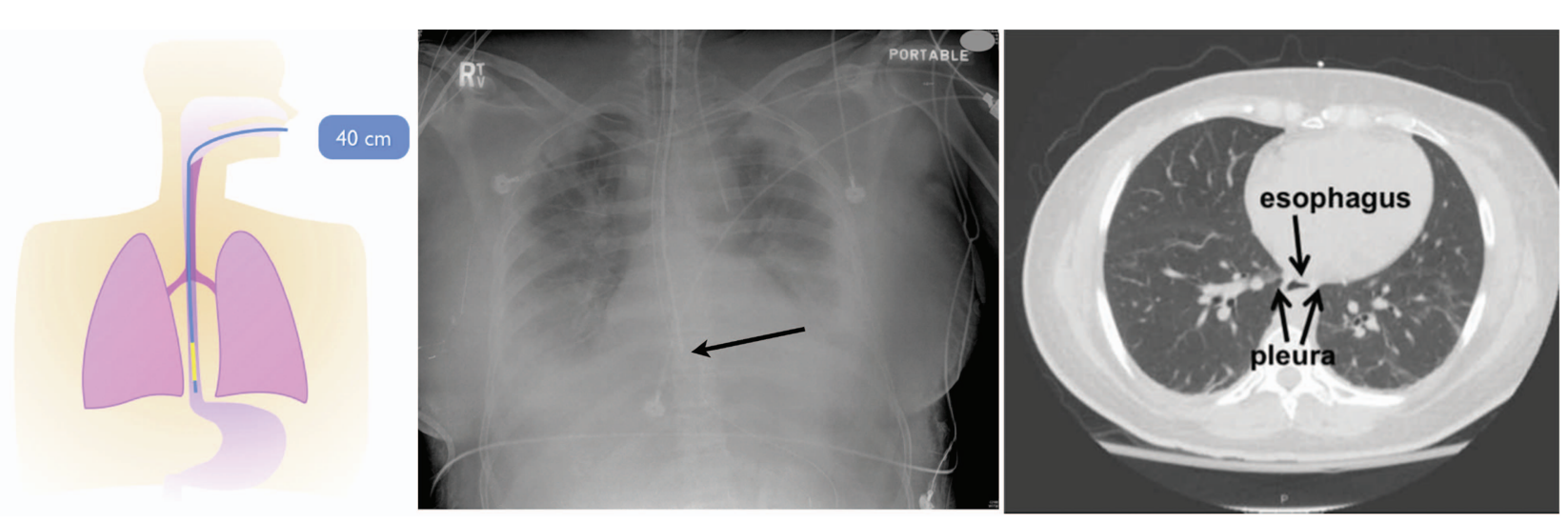

Fig. 6. Left: Correct positioning of the esophageal balloon, $\sim 40 \mathrm{~cm}$ from the lips. Center: Chest radiograph showing correct balloon placement (arrow). Right: Note that the esophagus borders the pleural space in the mid-thorax (arrows). Left and center images from Reference 19.

sessed during a gentle push on the abdomen with the airway occluded. Airway occlusion is accomplished using the expiratory pause control on the ventilator. When changes in $\mathrm{P}_{\mathrm{es}}$ are equal to airway pressure, it is assumed that transmission of $\mathrm{P}_{\mathrm{pl}}$ to $\mathrm{P}_{\mathrm{es}}$ is unimpeded, and $\mathrm{P}_{\mathrm{es}}$ accurately reflects $\mathrm{P}_{\mathrm{pl}}$. A chest radiograph can also be used to validate correct positioning (Fig. 6), ${ }^{19}$ but this is usually not necessary.

There are potential sources of error in the use of $\mathrm{P}_{\mathrm{es}}$ to estimate $\mathrm{P}_{\mathrm{pl}}{ }^{12,20}$ It is important to appreciate that the $\mathrm{P}_{\mathrm{es}}$ estimates $\mathrm{P}_{\mathrm{pl}}$ mid-thorax. The $\mathrm{P}_{\mathrm{pl}}$ is more negative in the non-dependent thorax and more positive in the dependent thorax (Fig. 7). The weight of the heart can bias the $\mathrm{P}_{\mathrm{es}}$ by as much as $5 \mathrm{~cm} \mathrm{H}_{2} \mathrm{O} .{ }^{16}$ The results of Guérin and Rich$\operatorname{ard}^{21}$ suggest that referencing absolute $\mathrm{P}_{\mathrm{es}}$ values to those obtained at the relaxation volume of the respiratory system might improve the customization of the correction of $\mathrm{P}_{\mathrm{es}}$ based on the physiologic and individual context, rather than using an invariant value of $5 \mathrm{~cm} \mathrm{H}_{2} \mathrm{O}$.

\section{Transpulmonary Pressure}

Transpulmonary pressure $\left(\mathrm{P}_{\mathrm{L}}\right)$ is the difference between pressure measured at the mouth and esophageal (pleural) pressure. During no flow (inspiratory or expiratory pause maneuvers), $\mathrm{P}_{\mathrm{L}}$ becomes the alveolar distending pressure. In this paper, the assumption is that $\mathrm{P}_{\mathrm{L}}$ is measured under static conditions and thus represents alveolar distending pressure. The ventilator should be set to avoid a negative $\mathrm{P}_{\mathrm{L}}$ during exhalation (contributing to cyclical opening and closing injury) and to avoid excessive $\mathrm{P}_{\mathrm{L}}$ at the end of inspiration (over-distention).

\section{Intra-Abdominal Pressure}

Interactions between the abdominal and thoracic compartments are important considerations in the critically ill

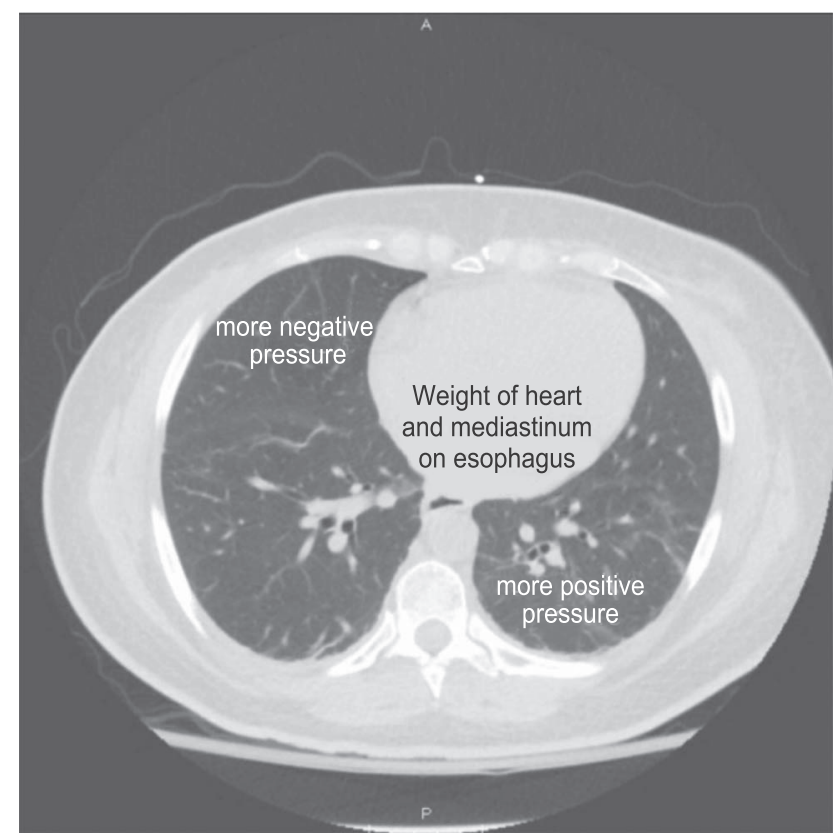

Fig. 7. Several potential sources of error in esophageal manometry are illustrated in this transverse section of the thorax. The esophageal pressure estimated pleural pressure $\left(P_{p l}\right)$ at mid-thorax. The $\mathrm{P}_{\mathrm{pl}}$ is more negative in the non-dependent thorax and less negative in the dependent thorax. Additionally, the weight of the heart and mediastinum will increase the pressure measured in the esophagus relative to $\mathrm{P}_{\mathrm{pl}}$.

patient, as the diaphragm links these compartments. ${ }^{17}$ If the diaphragm is allowed to freely shift upward into the thorax with increased abdominal pressure, lung volume will be reduced. If lung volume is restored with PEEP, the increased abdominal pressure will result in an increase in intrathoracic pressure. On average, half of the pressure in the intra-abdominal compartment (range of 25-80\%) has been noted to be present in the intrathoracic space..$^{22}$ This wide range in transmitted pressure is likely related to the amount of PEEP that has been applied to restore lung 

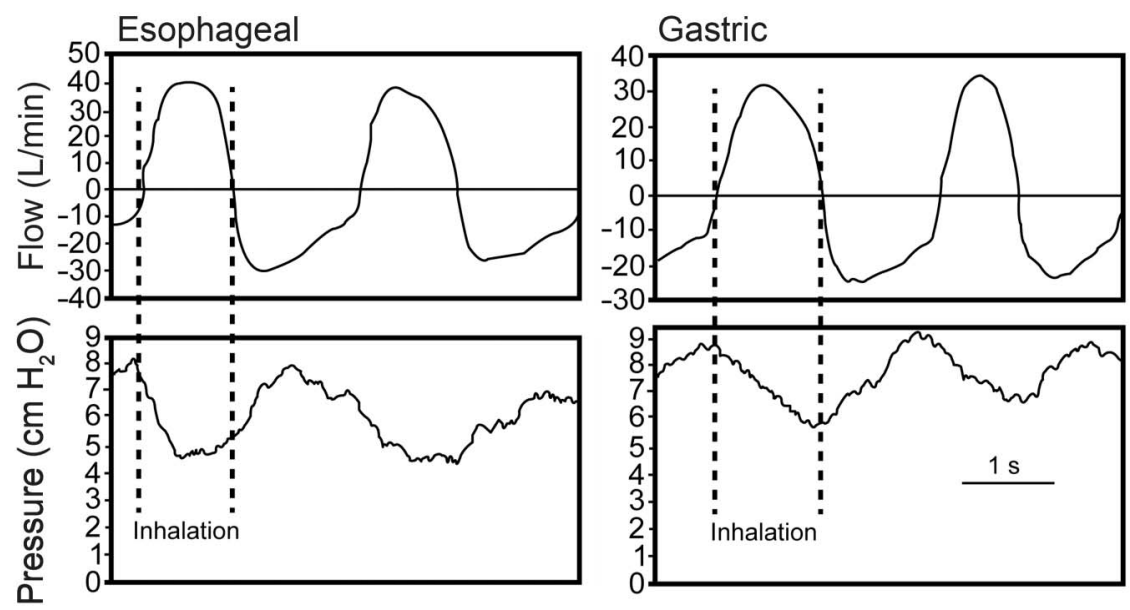

Fig. 8. Esophageal and gastric pressures. Positive flow represents inhalation, and negative flow represents exhalation. Both esophageal and gastric pressures decrease during inhalation, consistent with diaphragmatic paralysis. From Reference 28 , with permission.

volume. Sindi et al ${ }^{23}$ evaluated the correlation between esophageal and abdominal pressures in mechanically ventilated subjects undergoing laparoscopic surgery. In those subjects without respiratory disease, there was a significant but limited relationship between esophageal and abdominal pressures. They concluded that intra-abdominal pressure cannot predict $\mathrm{P}_{\mathrm{es}}$, but can provide complementary information useful in setting mechanical ventilation.

Intra-abdominal pressure is the steady-state pressure in the abdominal cavity. ${ }^{22}$ Normal intra-abdominal pressure is $5 \mathrm{~mm} \mathrm{Hg}$; it increases during inhalation with diaphragmatic contraction. Direct measurement of intraperitoneal pressure is the accepted standard for determination of intra-abdominal pressure. This is not practical, however; so the bladder method is thus most commonly used for intermittent intra-abdominal pressure measurement. ${ }^{24}$ The bladder is a passive structure, transmitting intra-abdominal pressure after infusion of saline volumes of $50-100 \mathrm{~mL}$. Intra-abdominal pressure should be measured at the end of exhalation in the supine position, ensuring that abdominal muscle contractions are absent and that the transducer is zeroed at the mid-axillary line.

In mechanically ventilated patients, an increase in intraabdominal pressure results in decreased $\mathrm{C}_{\mathrm{RS}}$ with flattening and a rightward shift of the $\mathrm{P}-\mathrm{V}$ curve of the respiratory system. ${ }^{22}$ These changes are due to decreased $\mathrm{C}_{\mathrm{CW}}$, whereas $\mathrm{C}_{\mathrm{L}}$ remains unchanged. A strong positive correlation between intra-abdominal pressure and the lower inflection point of the P-V curve of the respiratory system has also been reported in conditions with increased intraabdominal pressure, suggesting that intra-abdominal pressure might be correlated with the best PEEP in ventilated patients with ARDS and intra-abdominal hypertension. ${ }^{22}$ In deeply sedated patients with ARDS, the diaphragm behaves as a passive structure, and thus moves upward in the rib cage, transmits increased intra-abdominal pressure to the lower lobes of the lung, and causes compression atelectasis. Surgical abdominal decompression recruits lung volume and increases in $\mathrm{P}_{\mathrm{aO}_{2}} / \mathrm{F}_{\mathrm{IO}_{2}}{ }^{25}$ Upright positioning increases intra-abdominal pressure and decreases $\mathrm{C}_{\mathrm{RS}}$, suggesting that this position might result in a deterioration of respiratory function in patients with intraabdominal hypertension. ${ }^{26}$

\section{Transdiaphragmatic Pressure}

Normally during spontaneous inspiration, $\mathrm{P}_{\mathrm{pl}}$ decreases and intra-abdominal pressure increases. Transdiaphragmatic pressure $\left(\mathrm{P}_{\mathrm{di}}\right)$ represents the pressure across the diaphragm, the difference between abdominal pressure $\left(\mathrm{P}_{\mathrm{ab}}\right)$ and $\mathrm{P}_{\mathrm{pl}}: \mathrm{P}_{\mathrm{di}}=\mathrm{P}_{\mathrm{ab}}-\mathrm{P}_{\mathrm{pl}}$. Abdominal pressure is measured from a catheter in the stomach (gastric pressure), and $\mathrm{P}_{\mathrm{pl}}$ is measured as $\mathrm{P}_{\mathrm{es}}$. Sharshar et $\mathrm{al}^{27}$ reported that $\mathrm{P}_{\mathrm{di}}$-driven servo ventilation was well synchronized to the subjects' effort, delivering a pressure proportional to $\mathrm{P}_{\mathrm{di}}$ and reducing respiratory effort at normocapnia and hypercapnia. Although this approach has physiologic intrigue, it might not be practical for routine clinical use.

Abdominal paradox is a clinical sign of diaphragm paralysis. In this circumstance, both esophageal and gastric pressures have a negative deflection during inspiration, suggestive of diaphragmatic paralysis (Fig. 8). ${ }^{28}$

\section{Asynchrony}

Patient-ventilator asynchrony results in an airway pressure waveform that varies from breath to breath, particularly during volume control ventilation (Fig. 9). ${ }^{29}$ A special form of patient-ventilator asynchrony can occur during pressure support ventilation, in which the patient actively exhales to terminate the inspiratory phase. This is seen as 


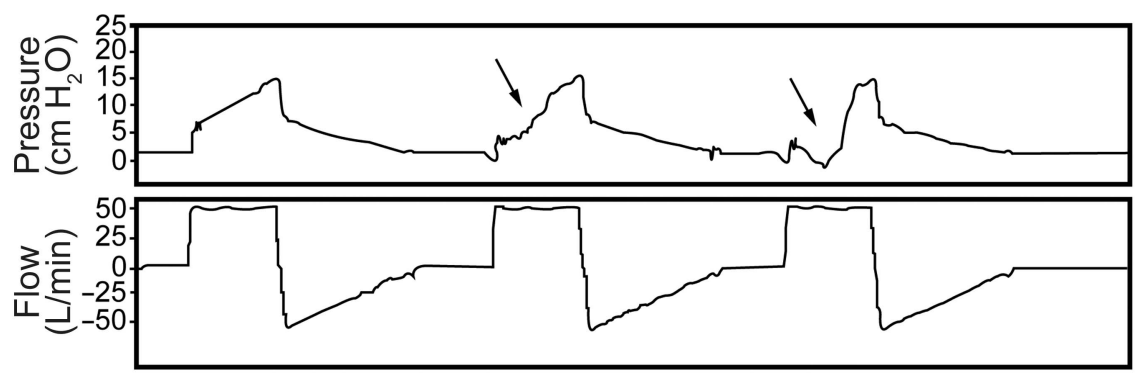

Fig. 9. Effect of asynchrony on the airway pressure waveform during volume control ventilation. The arrows indicate a decrease in airway pressure due to the fixed flow from the ventilator and the increased patient effort. From Reference 29.

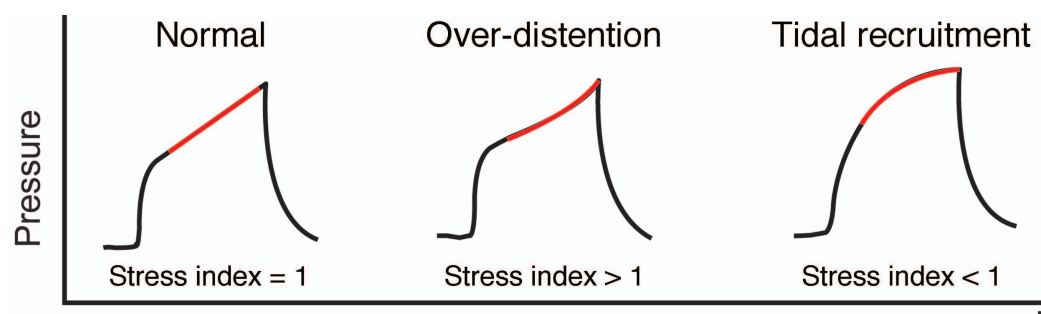

Time

Fig. 10. Normal stress index, stress index with over-distention, and stress index with tidal recruitment.

a pressure spike at the end of inspiration, causing the ventilator to pressure-cycle to the expiratory phase. It is important to judge the presence of asynchrony when assessing respiratory mechanics, as this has the potential to bias assessments of respiratory mechanics such as $\mathrm{P}_{\text {plat }}$ and stress index.

\section{Stress Index}

The stress index is used to assess the shape of the pressure-time curve during constant flow-volume control ventilation (Fig. 10). ${ }^{30} \mathrm{~A}$ linear increase in pressure (constant compliance, stress index $=1$ ) suggests adequate alveolar recruitment without over-distention. If compliance worsens as the lungs are inflated (progressive decrease in compliance, upward concavity, stress index $>1$ ), this suggests over-distention, and the recommendation is to decrease the PEEP, $\mathrm{V}_{\mathrm{T}}$, or both. If compliance improves as the lungs are inflated (progressive increase in compliance, downward concavity, stress index $<1$ ), this suggests tidal recruitment and potential for additional recruitment, and the recommendation is to increase PEEP.

The stress index is the coefficient $b$ of a power equation $^{30}: \mathrm{P}=\mathrm{a} \times \mathrm{T}_{\mathrm{I}}^{\mathrm{b}}+\mathrm{c}$, where the coefficient $\mathrm{b}$ (stress index) describes the shape of the curve. Using this equation, the stress index can be determined by curve-fitting this equation during passive constant-flow inflation (Fig. 11). One manufacturer has the stress index equation incorporated into the software of the ventilator to allow display of the stress index. Alternatively, one can examine the shape of the airway pressure waveform displayed on the ventilator (Fig. 12). The results of a recent study using computed tomography to identify over-distention reported that injurious ventilation was associated with a $\mathrm{P}_{\text {plat }}$ of $>25 \mathrm{~cm} \mathrm{H}_{2} \mathrm{O}$ and a stress index of $>1.05 .^{6}$

\section{Flow and Volume}

\section{Time Constant}

An important principle for understanding pulmonary mechanics is that of the time constant. The time constant determines the rate of change in the volume of a lung unit that is passively inflated or deflated. It is expressed by the relationship: $\mathrm{V}_{\mathrm{t}}=\mathrm{V}_{\mathrm{i}} \times \mathrm{e}^{-\mathrm{t} / \tau}$, where $\mathrm{V}_{\mathrm{t}}$ is the volume of a lung unit at time $t, \mathrm{~V}_{\mathrm{i}}$ is the initial volume of the lung unit, $\mathrm{e}$ is the base of the natural logarithm, and $\tau$ is the time constant. For respiratory mechanics, $\tau$ is the product of resistance and compliance. Lung units with a higher resistance and/or compliance will have a longer time constant and require more time to fill and to empty. In contrast, lung units with a lower resistance and/or compliance will have a lower time constant and thus require less time to fill and to empty. There is a $63 \%$ volume change in $1 \tau$, an $87 \%$ volume change in $2 \tau$, a $95 \%$ volume change in $3 \tau$, a $98 \%$ volume change in $4 \tau$, and $>99 \%$ volume change in $5 \tau$. 

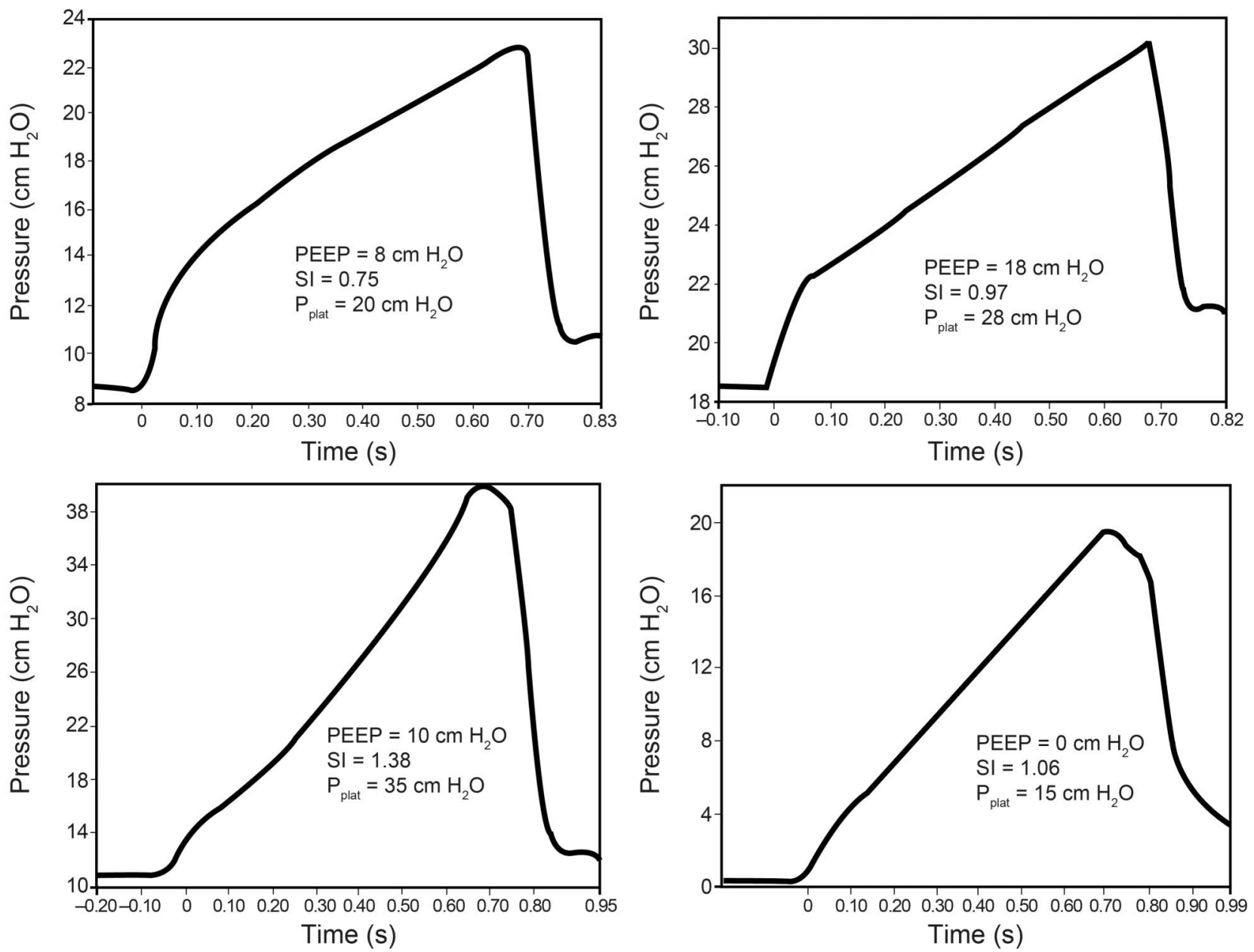

Fig. 11. Top: Stress index (SI) in a patient early in the course of ARDS. In this case, the stress index improved as PEEP was increased. Bottom: Stress index in a patient late in the course of ARDS. In this case, the stress index improved as PEEP was decreased. $P_{\text {plat }}=$ plateau pressure. From Reference 31.
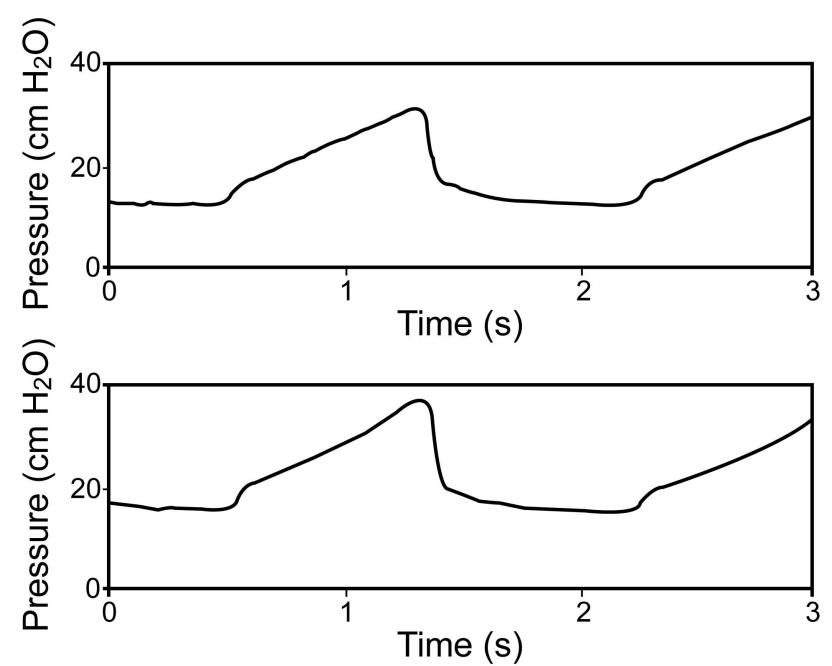

Fig. 12. Top: Ventilator pressure waveform with a PEEP of $12 \mathrm{~cm} \mathrm{H}_{2} \mathrm{O}$. Note the linear increase in pressure. Bottom: Ventilator pressure waveform after PEEP was increased to $15 \mathrm{~cm} \mathrm{H}_{2} \mathrm{O}$. Note the upward concavity in pressure.
A simple method to measure the $\tau_{\mathrm{E}}$ is to divide the exhaled $\mathrm{V}_{\mathrm{T}}$ by the peak expiratory flow $\left(\dot{\mathrm{V}}_{\mathrm{EXH}}\right)$ during passive positive-pressure ventilation ${ }^{32}: \tau_{\mathrm{E}}=$ exhaled $\mathrm{V}_{\mathrm{T}} / \dot{\mathrm{V}}_{\mathrm{EXH}}$. Although this is a useful index of the global $\tau_{\mathrm{E}}$, it treats the lungs as a single compartment and thus does not account for time constant heterogeneity in the lungs.

\section{Inspiratory Flow}

All current-generation critical care ventilators monitor flow. Although some monitor flow with a pneumotachometer directly at the proximal airway, most monitor $\dot{V}_{I}$ at the inspiratory valve and $\dot{V}_{\mathrm{E}}$ at the expiratory valve. ${ }^{3}$

During volume control ventilation, the $\dot{\mathrm{V}}_{\mathrm{I}}$ is that which is set on the ventilator. During passive pressure control ventilation, flow is the pressure applied to the airway, $R_{a w}$, and $\tau$ (Fig. 13): $\dot{\mathrm{V}}_{\mathrm{I}}=\left(\Delta \mathrm{P} / \mathrm{R}_{\mathrm{aw}}\right) \times \mathrm{e}^{-\mathrm{t} / \tau}$, where $\Delta \mathrm{P}$ is the pressure applied to the airway above PEEP, $t$ is the elapsed 

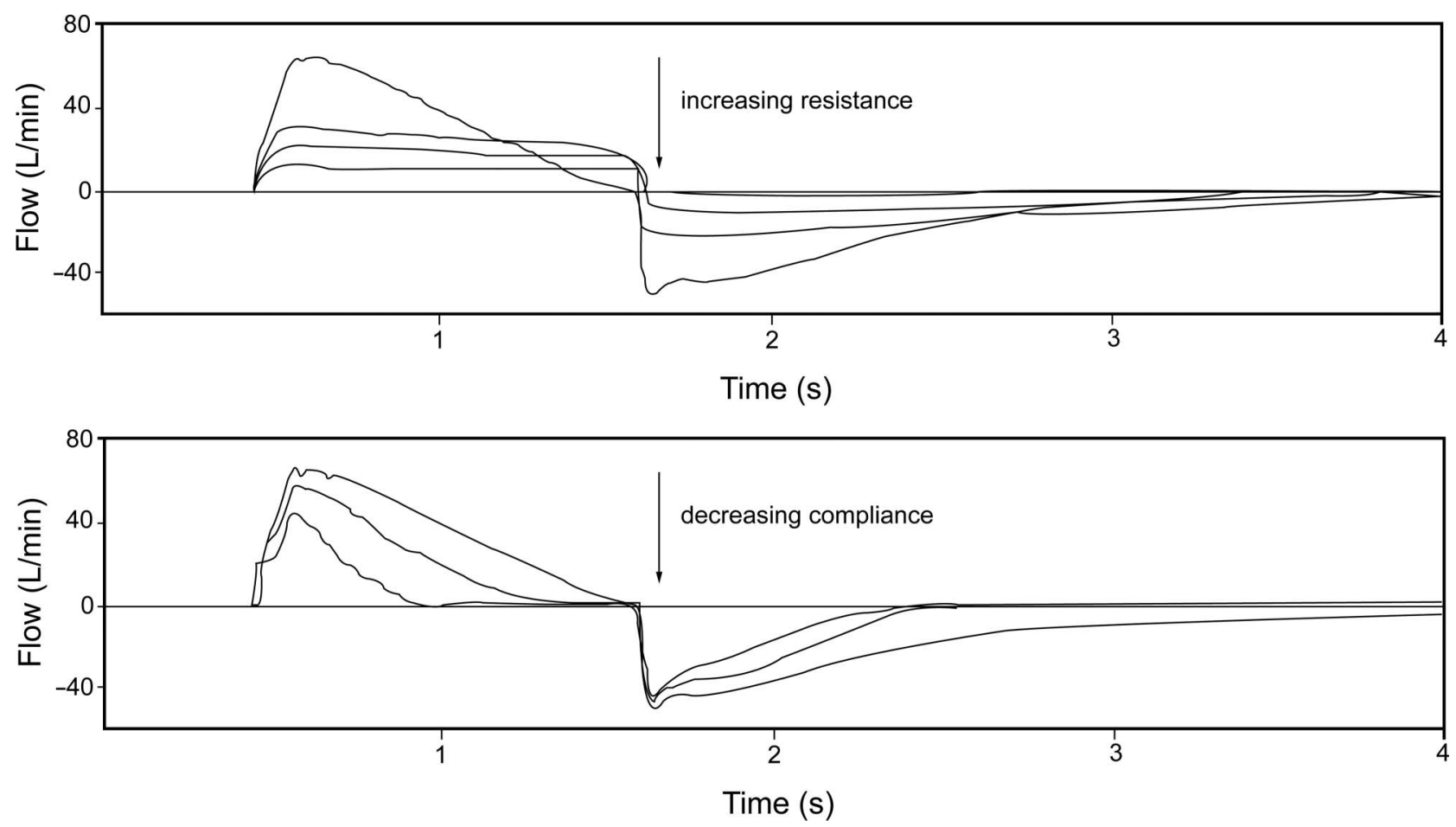

Fig. 13. Flow shapes at different mechanical loads during pressure control ventilation. Top: Resistance variations. Bottom: Compliance variations. From Reference 4.

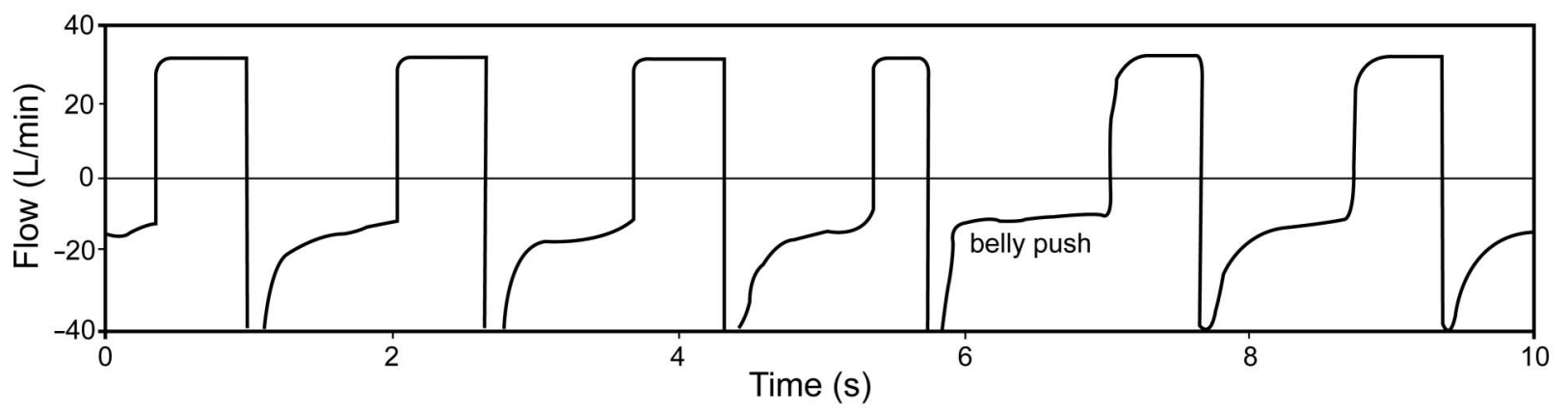

Fig. 14. Effect of increased intra-abdominal pressure on expiratory flow in a patient with flow limitation. Note that there is no change in expiratory flow as intra-abdominal (and hence intrathoracic) pressure increases.

time after initiation of the inspiratory phase, and $e$ is the base of the natural logarithm.

\section{Expiratory Flow}

Expiratory flow is normally passive and is determined by $\mathrm{P}_{\mathrm{alv}}, \mathrm{R}_{\mathrm{aw}}$, the elapsed time since initiation of exhalation, and $\tau: \dot{V}=-\left(\mathrm{P}_{\text {alv }} / \mathrm{R}_{\mathrm{aw}}\right) \times \mathrm{e}^{-\mathrm{t} / \tau}$. Note that, by convention, expiratory flow is negative, and inspiratory flow is positive.

End-expiratory flow is present if $R_{a w}$ is high and $T_{E}$ is not sufficient, indicating the presence of air trapping (autoPEEP). It may be of value to determine whether autoPEEP is due to flow limitation. If pushing on the abdomen results in no additional expiratory flow, flow limitation is present (Fig. 14). ${ }^{33}$ The presence of missed triggers and flow limitation suggests that PEEP might effectively counterbalance auto-PEEP (Fig. 15). Notching in the expiratory flow waveform suggests the presence of missed trigger efforts (Fig. 16).

\section{Tidal Volume}

Critical care ventilators do not measure volume directly, but derive this from integration of flow. Because flow is usually not measured directly at the proximal airway, volume output from the ventilator is less than the volume delivered to the patient. Modern critical care ventilators correct volume for circuit compression, so the volume displayed by the ventilator closely approximates the vol- 


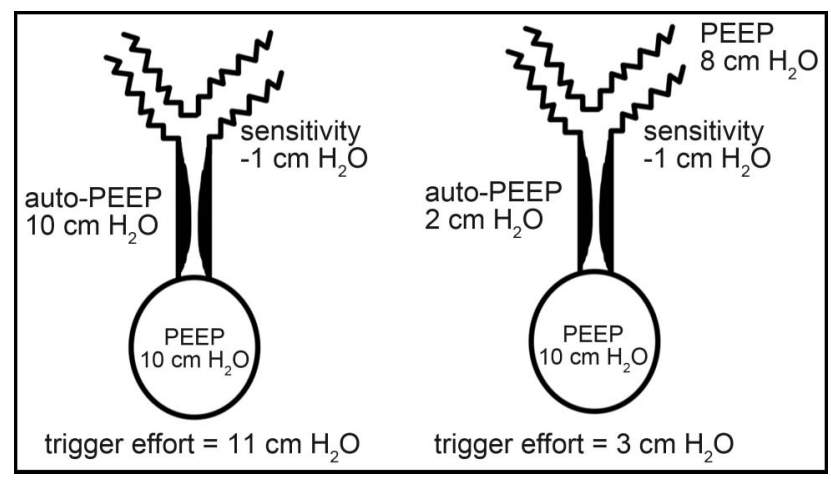

Fig. 15. Effect of PEEP, auto-PEEP, and trigger effort in the setting of flow limitation.

ume delivered to the patient. The volume waveform may be useful to detect the presence of a leak (eg, bronchopleural fistula, leak around the cuff, leak around the mask), which results in a difference between the inspiratory and expiratory $\mathrm{V}_{\mathrm{T}}$. Bolzan et $\mathrm{l}^{34}$ reported a method for managing endotracheal tube cuff inflation using volume-time graphics.

\section{End-Expiratory Lung Volume}

Calculation of end-expiratory lung volume is based on a step change in $\mathrm{F}_{\mathrm{IO}_{2}}$ and the assumption that $\mathrm{N}_{2}$ is the balance gas. ${ }^{35,36}$ Baseline determination is made of end-tidal $\mathrm{N}_{2}\left(\mathrm{~F}_{\mathrm{ETN}_{2}}\right)$. It is assumed that oxygen consumption and carbon dioxide production remain constant throughout the measurement. A step change in $\mathrm{F}_{\mathrm{IO}_{2}}$ then occurs, and the end-expiratory lung volume is calculated as: $\Delta \mathrm{V}_{\mathrm{N}_{2}} / \Delta \mathrm{F}_{\mathrm{ETN}_{2}}$, where $\Delta \mathrm{F}_{\mathrm{ETN}_{2}}$ is the change following the step change in $\mathrm{F}_{\mathrm{IO}_{2}}$. The breath-to-breath changes are calculated over $\sim 20$ breaths. The end-expiratory lung volume measurement is commercially available on the Engström Carestation (FRC INview, GE Healthcare, Madison, Wisconsin). For this application, nitrogen concentration in inhaled and exhaled gas is not directly measured, but estimated from the endtidal concentrations of oxygen and carbon dioxide.

The use of end-expiratory lung volume during PEEP titration would seem attractive. However, a PEEP-induced increase in end-expiratory lung volume might be the result of recruitment, or it might be the result of over-distention of already open alveoli. Thus, end-expiratory lung volume by itself might not be useful to assess PEEP response.

\section{Derived Measurements}

\section{Respiratory System Compliance}

$\mathrm{C}_{\mathrm{RS}}$ is calculated as the $\mathrm{V}_{\mathrm{T}}$ divided by the pressure required: $\mathrm{C}_{\mathrm{RS}}=\Delta \mathrm{V} / \Delta \mathrm{P}=\mathrm{V}_{\mathrm{T}} /\left(\mathrm{P}_{\text {plat }}-\mathrm{PEEP}\right)$, where $\Delta \mathrm{V}$ is volume change. Acceptable $\mathrm{C}_{\mathrm{RS}}$ is $50-100 \mathrm{~mL} / \mathrm{cm} \mathrm{H}_{2} \mathrm{O}$ in mechanically ventilated patients. It is determined by the compliance of the lungs and chest wall.
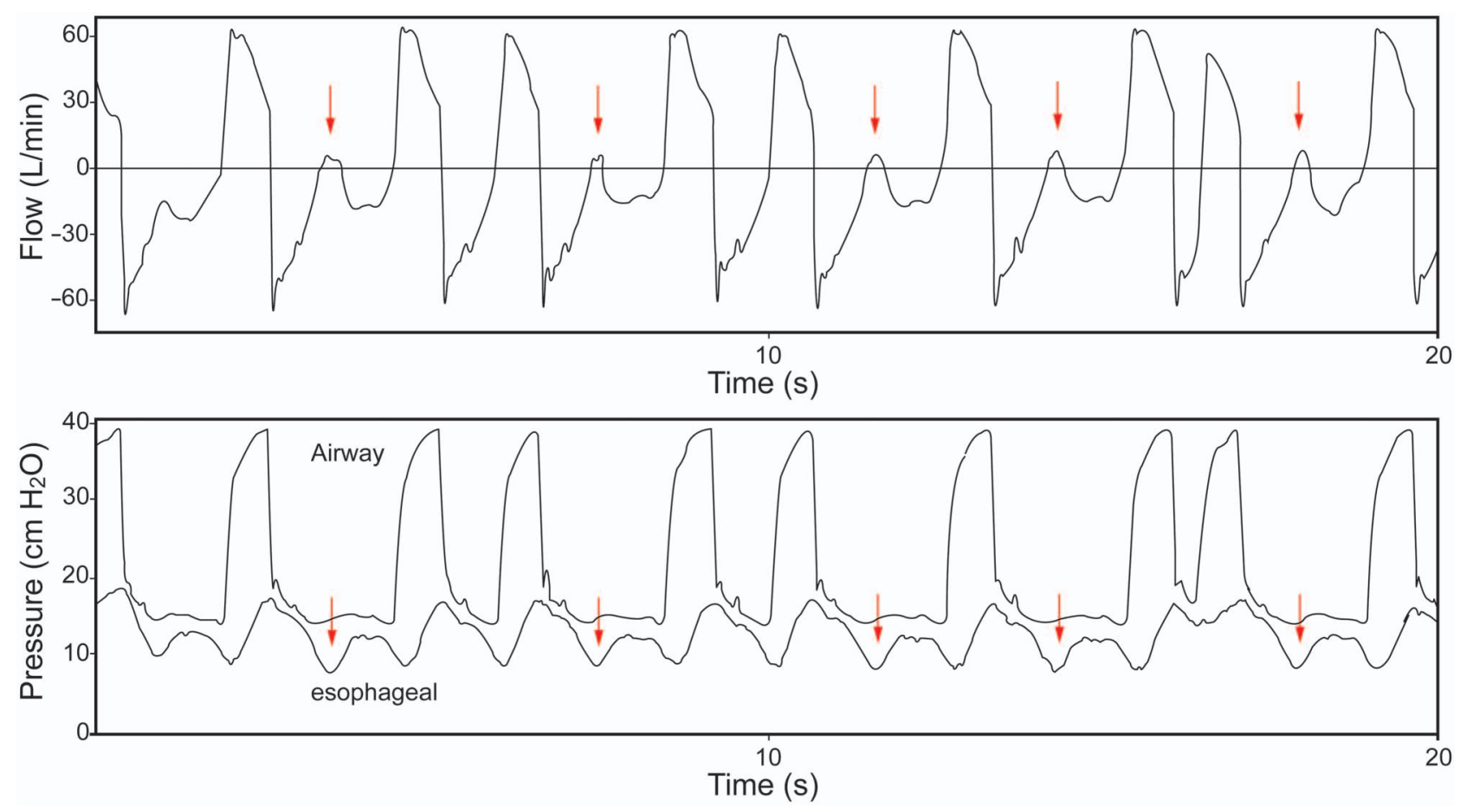

Fig. 16. Flow (top) and airway pressure and esophageal pressure (bottom) in a patient with severe COPD. The arrows represent missed triggers. 
$\mathrm{C}_{\mathrm{RS}}$ has been used to determine the optimal level of PEEP in patients with ARDS; the highest level of $\mathrm{C}_{\mathrm{RS}}$ corresponds to best PEEP. In 1975, Suter et al ${ }^{37}$ reported that the PEEP that resulted in the maximum oxygen delivery and the lowest dead-space fraction also resulted in the greatest $C_{R S}$. The optimal PEEP ranged from 0 to $15 \mathrm{~cm} \mathrm{H}_{2} \mathrm{O}$. Mixed venous $\mathrm{P}_{\mathrm{O}_{2}}$ increased between 0 PEEP and the PEEP that resulted in maximum oxygen delivery, but then decreased at higher PEEP. The authors concluded that $\mathrm{C}_{\mathrm{RS}}$ could be used to determine the optimal PEEP.

The optimal PEEP is that which results in the lowest driving pressure $\left(\mathrm{P}_{\text {plat }}-\right.$ PEEP) if $\mathrm{V}_{\mathrm{T}}$ is kept constant. Mercat et al ${ }^{38}$ used an approach in which PEEP was set as high as possible without increasing $\mathrm{P}_{\text {plat }}$ above 28$30 \mathrm{~cm} \mathrm{H}_{2} \mathrm{O}$. Using this approach, higher PEEP is likely set to best compliance because compliance increases with alveolar recruitment. With over-distention, compliance decreases, and $\mathrm{P}_{\text {plat }}$ is more likely to be $>30 \mathrm{~cm} \mathrm{H}_{2} \mathrm{O}$. This approach for setting PEEP did not significantly reduce mortality, but it did improve lung function and reduced the duration of mechanical ventilation and organ failure.

Pintado et $\mathrm{al}^{39}$ recently reported a randomized controlled study to evaluate the effect of setting an individualized PEEP at the highest $C_{R S}$. Subjects in the $\mathrm{C}_{\mathrm{RS}}$-guided group had a nonsignificant improvement in 28-d mortality ( $21 \%$ vs $39 \%, P=.12$ ), perhaps because the study was underpowered. Multiple-organ dysfunction-free days (median of 6 vs $20.5 \mathrm{~d}, P=.02$ ), respiratory failure-free days (median of 7.5 vs $14.5 \mathrm{~d}, P=.03$ ), and hemodynamic failure-free days (median of $16 \mathrm{vs} 22 \mathrm{~d}, P=.04$ ) at $28 \mathrm{~d}$ were significantly lower in subjects with a $\mathrm{C}_{\mathrm{RS}}$-guided setting of PEEP.

\section{Chest-Wall Compliance}

To calculate $\mathrm{C}_{\mathrm{CW}}$, changes in $\mathrm{P}_{\mathrm{es}}\left(\mathrm{P}_{\mathrm{pl}}\right)$ are used during passive inflation ${ }^{17}: \mathrm{C}_{\mathrm{CW}}=\Delta \mathrm{V} / \Delta \mathrm{P}=\mathrm{V}_{\mathrm{T}} / \Delta \mathrm{P}_{\mathrm{es}}$. The patient data in Figure 17 can be used to calculate $\mathrm{C}_{\mathrm{CW}}: \mathrm{C}_{\mathrm{CW}}=$ $320 \mathrm{~mL} / 4 \mathrm{~cm} \mathrm{H}_{2} \mathrm{O}=80 \mathrm{~mL} / \mathrm{cm} \mathrm{H}_{2} \mathrm{O}$. Normal $\mathrm{C}_{\mathrm{CW}}$ is $200 \mathrm{~mL} / \mathrm{cm} \mathrm{H}_{2} \mathrm{O}$ and is decreased due to morbid obesity, abdominal compartment syndrome, chest-wall edema, chest-wall burns, and thoracic deformities (eg, kyphoscoliosis). $\mathrm{C}_{\mathrm{CW}}$ is also decreased with an increase in muscle tone (eg, a patient who is asynchronous with the ventilator). $\mathrm{C}_{\mathrm{CW}}$ is increased with flail chest and paralysis.

\section{Lung Compliance}

To calculate $\mathrm{C}_{\mathrm{L}}$, the change in $\mathrm{P}_{\mathrm{L}}$ when the lungs are inflated is used: $\mathrm{C}_{\mathrm{L}}=\Delta \mathrm{V} / \Delta \mathrm{P}=\mathrm{V}_{\mathrm{T}} / \Delta \mathrm{P}_{\mathrm{L}}$. Normal $\mathrm{C}_{\mathrm{L}}$ is $200 \mathrm{~mL} / \mathrm{cm} \mathrm{H}_{2} \mathrm{O} . \mathrm{C}_{\mathrm{L}}$ is decreased with ARDS, cardiogenic pulmonary edema, pneumothorax, consolidation, atelecta- sis, pulmonary fibrosis, pneumonectomy, bronchial intubation, and over-distention. $\mathrm{C}_{\mathrm{L}}$ is increased with emphysema.

The patient data in Figure 17 can be used to illustrate these calculations:

$$
\begin{aligned}
\mathrm{C}_{\mathrm{RS}}=320 \mathrm{~mL} /\left(40 \mathrm{~cm} \mathrm{H}_{2} \mathrm{O}-26 \mathrm{~cm} \mathrm{H}_{2} \mathrm{O}\right) & \\
= & 23 \mathrm{~mL} / \mathrm{cm} \mathrm{H}_{2} \mathrm{O}
\end{aligned}
$$

$\mathrm{C}_{\mathrm{CW}}=320 \mathrm{~mL} / 4 \mathrm{~cm} \mathrm{H} \mathrm{H}_{2} \mathrm{O}=80 \mathrm{~mL} / \mathrm{cm} \mathrm{H}_{2} \mathrm{O}$

$\mathrm{C}_{\mathrm{L}}=320 \mathrm{~mL} / 10 \mathrm{~cm} \mathrm{H}_{2} \mathrm{O}=32 \mathrm{~mL} / \mathrm{cm} \mathrm{H}_{2} \mathrm{O}$

These calculations can be crosschecked in the following manner: $1 / \mathrm{C}_{\mathrm{RS}}=1 / \mathrm{C}_{\mathrm{CW}}+1 / \mathrm{C}_{\mathrm{L}}$ and $1 / 23 \approx 1 / 80+1 / 32$. In this example, $\mathrm{C}_{\mathrm{L}}$ and $\mathrm{C}_{\mathrm{CW}}$ are both decreased, but $\mathrm{C}_{\mathrm{L}}$ is the most compromised.

\section{Airway Resistance}

During volume control ventilation, $R_{I}$ can be estimated from the PIP, $\mathrm{P}_{\text {plat }}$, and end-inspiratory flow: $\mathrm{R}_{\mathrm{I}}=(\mathrm{PIP}-$ $\left.\mathrm{P}_{\text {plat }}\right) / \dot{\mathrm{V}}_{\mathrm{I}} \cdot \mathrm{R}_{\mathrm{E}}$ can be estimated from the $\dot{\mathrm{V}}_{\mathrm{EXH}}$ and the difference between $\mathrm{P}_{\text {plat }}$ and PEEP ${ }^{40}: \mathrm{R}_{\mathrm{E}}=\left(\mathrm{P}_{\text {plat }}-\mathrm{PEEP}\right) /$ $\dot{V}_{\text {EXH }}$. Common causes of increased $R_{a w}$ are bronchospasm, secretions, and a small inner diameter endotracheal tube. For intubated and mechanically ventilated patients, $R_{I}$ should be $<10 \mathrm{~cm} \mathrm{H}_{2} \mathrm{O} / \mathrm{L} / \mathrm{s}$. $R_{E}$ is typically greater than $\mathrm{R}_{\mathrm{I}}$.

The patient data in Figure 17 can be used to illustrate these calculations:

$\mathrm{R}_{\mathrm{I}}=\left(43 \mathrm{~cm} \mathrm{H} \mathrm{H}_{2} \mathrm{O}-40 \mathrm{~cm} \mathrm{H} \mathrm{H}_{2} \mathrm{O}\right) / 0.33 \mathrm{~L} / \mathrm{s}$

$$
=9 \mathrm{~cm} \mathrm{H}_{2} \mathrm{O} / \mathrm{L} / \mathrm{s}
$$

$\mathrm{R}_{\mathrm{E}}=\left(40 \mathrm{~cm} \mathrm{H} \mathrm{H}_{2} \mathrm{O}-26 \mathrm{~cm} \mathrm{H} \mathrm{H}_{2} \mathrm{O}\right) / 0.83 \mathrm{~L} / \mathrm{s}$

$$
=17 \mathrm{~cm} \mathrm{H} \mathrm{H}_{2} \mathrm{O} / \mathrm{L} / \mathrm{s}
$$

\section{Work of Breathing}

The Campbell diagram (Fig. 18) includes the effects of $\mathrm{C}_{\mathrm{CW}}, \mathrm{C}_{\mathrm{L}}$, and $\mathrm{R}_{\mathrm{aw}}$ on WOB. ${ }^{41}$ Note that WOB is increased with decreased $C_{C W}$, decreased $C_{L}$, or increased $R_{a w}$. WOB requires an esophageal balloon to properly quantify, and for that reason, it is not frequently measured. It is not clear that measuring WOB improves patient outcome. Normal WOB is $0.3-0.7 \mathrm{~J} / \mathrm{L}$.

The algorithm for proportional assist ventilation of the Puritan-Bennett 840 ventilator estimates compliance and 

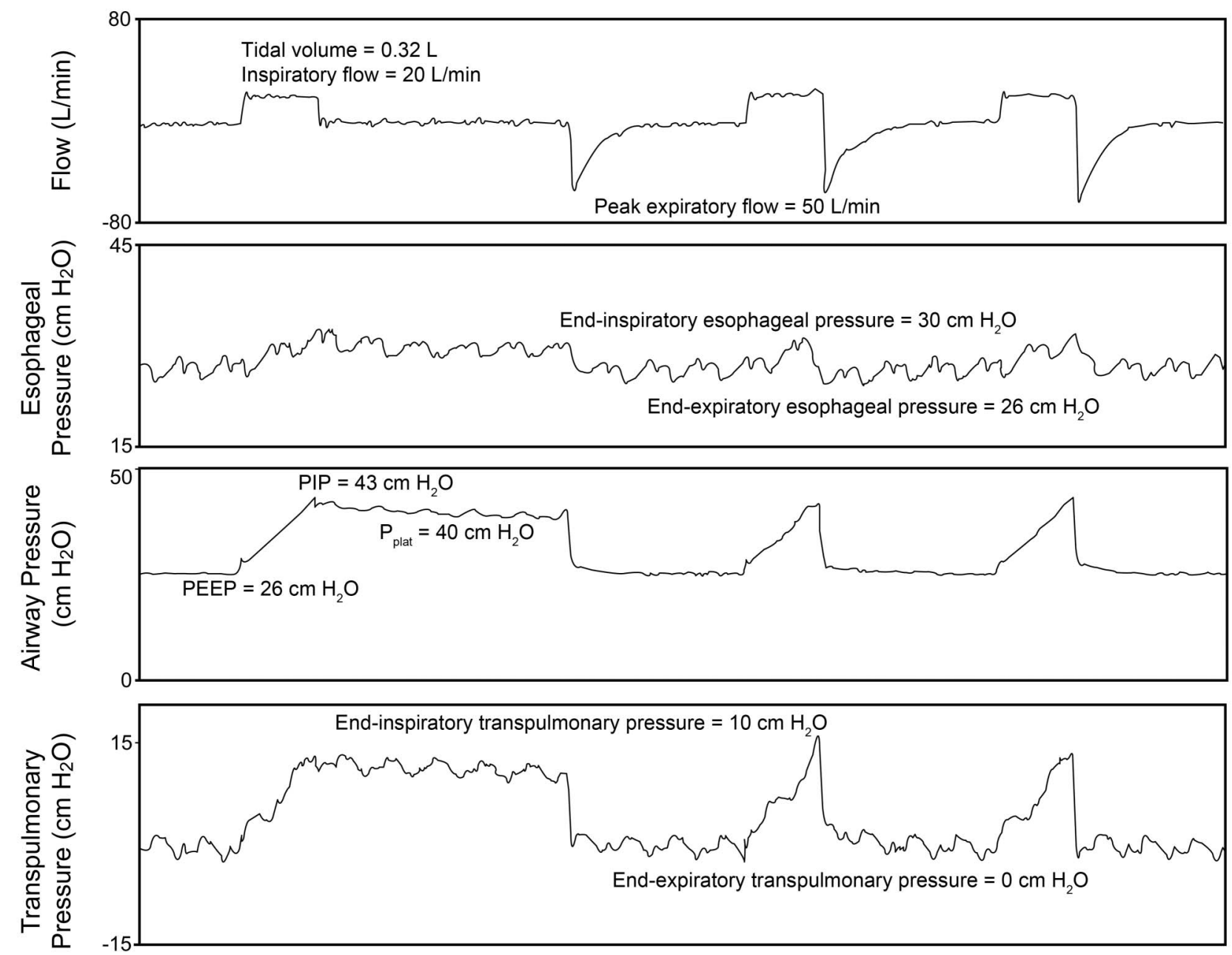

Fig. 17. Flow, esophageal pressure, airway pressure, and transpulmonary pressure can be used to calculate respiratory system compliance, chest-wall compliance, lung compliance, inspiratory airway resistance, and expiratory airway resistance. See text for details. PIP $=$ peak inspiratory pressure; $\mathrm{P}_{\text {plat }}=$ plateau pressure.

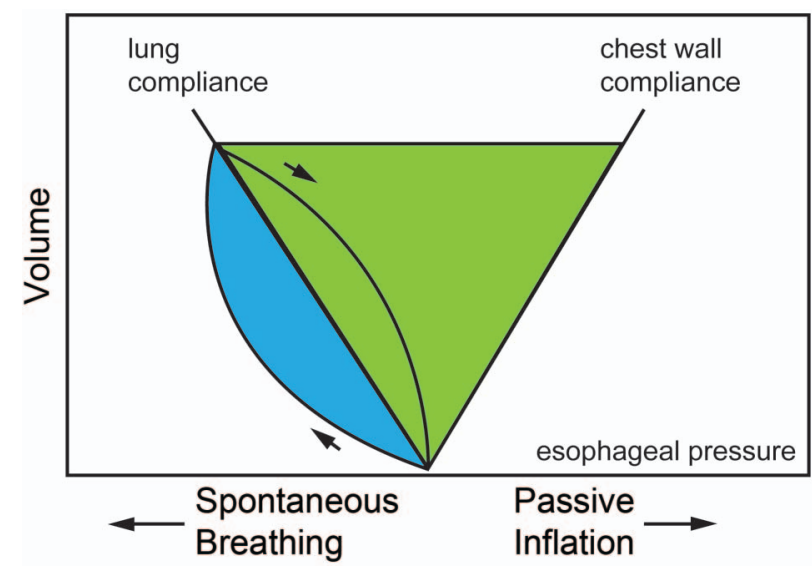

Fig. 18. Campbell diagram as used to calculate work of breathing (WOB). The green area represents elastic WOB, and the blue area represents resistive WOB. The total shaded area represents total WOB. resistance by performing a 300-ms inspiratory pause every $8-15$ breaths. $\dot{\mathrm{V}}_{\mathrm{I}}$ is measured and instantaneously integrated to volume. WOB is calculated from the measured $\dot{\mathrm{V}}_{\mathrm{I}}$ and the $\mathrm{P}$ calculated from the equation of motion: $\mathrm{WOB}=\int \mathrm{P} \times \mathrm{V}$. Power of breathing $(\mathrm{WOB} / \mathrm{min})$ is the rate at which work is done as a measure over time, not for an individual breath. ${ }^{42-46}$ This may be a better assessment of respiratory muscle load than WOB/breath. Normal power of breathing is $4-8 \mathrm{~J} / \mathrm{min}$. An artificial neural network can be used to estimate power of breathing noninvasively, without the need for an esophageal catheter in patients with respiratory failure. ${ }^{42}$ In one study, a WOB $/ \mathrm{min}$ of $<10 \mathrm{~J} / \mathrm{min}$ was predictive of subjects' ability to be liberated from mechanical ventilation..$^{43}$

Adaptive support ventilation (ASV) is based on the concept of minimum WOB, which suggests that the patient will breathe at a $\mathrm{V}_{\mathrm{T}}$ and breathing frequency that minimize the elastic and resistive loads while maintaining oxygen- 
ation and acid/base balance. ${ }^{35,47}$ This uses the approach described by Otis to determine the breathing frequency associated with the lowest WOB. Of note, Otis based his data on the patient, whereas adaptive support ventilation is based on the ventilator. The target breathing frequency is determined by respiratory mechanics and alveolar ventilation.

With ASV, the ventilator attempts to deliver 100 $\mathrm{mL} / \mathrm{min} / \mathrm{kg}$ of minute ventilation, adjustable from $25 \%$ to $350 \%$, which allows the clinician to provide full support or encourage spontaneous breathing. $\mathrm{V}_{\mathrm{T}}$ is determined by dividing the target $\dot{V}_{\mathrm{E}}$ by the target rate. Note that a higher breathing frequency (and lower $\mathrm{V}_{\mathrm{T}}$ ) will be targeted for low compliance (low $\tau$ ), whereas a lower breathing frequency (and higher $\mathrm{V}_{\mathrm{T}}$ ) will be targeted for a high resistance (high $\tau$ ). This is observed clinically, where patients with pulmonary fibrosis breath rapidly and shallowly. For patients with COPD with a high $\tau$, the WOB is less with a lower breathing frequency. For ASV, the ventilator also adjusts the inspiratory-expiratory ratio and $\mathrm{T}_{\mathrm{I}}$ of the mandatory breaths by calculation of the $\tau_{\mathrm{E}}$, as described above, to maintain sufficient $\mathrm{T}_{\mathrm{E}}(3 \times \tau)$. During spontaneous breathing, ASV controls only the pressure of pressure support breaths.

\section{Pressure-Volume Curves}

$\mathrm{P}-\mathrm{V}$ curves are displayed with volume as a function of pressure. ${ }^{36,48}$ The slope of the $\mathrm{P}-\mathrm{V}$ curve is $\mathrm{C}_{\mathrm{RS}}$. The most common methods used to measure pressure-volume curves are the use of a super syringe, inflation with a constant slow flow $\left(<10 \mathrm{~L} / \mathrm{min}\right.$ ), and $\mathrm{P}_{\text {plat }}$ at various inflation volumes. Correct interpretation of the P-V curve during non-constant-flow ventilation (eg, pressure control ventilation) and with higher $\dot{\mathrm{V}}_{\mathrm{I}}$ is problematic. Several current-generation ventilators are able to measure $\mathrm{P}-\mathrm{V}$ curves using a slow inflation technique at several levels of PEEP to assess alveolar recruitment and inflection points to determine the appropriate level of PEEP.

An approach for setting PEEP is based on inflection points determined from the P-V curve (Fig. 19).49,50 The lower inflection point is thought to represent the pressure at which a large number of alveoli are recruited, and the upper inflection point is thought to indicate overdistention. However, recruitment is likely to occur along the entire inflation P-V curve, and the upper inflection point might represent the end of recruitment rather than over-distention.

A number of issues preclude routine use of pressurevolume curves to set the ventilator in patients with ARDS. ${ }^{31,48,51,52}$ Measurement of the pressure-volume curve requires sedation, and often paralysis, to correctly make the measurement. Precise identification of inflection points may require mathematical curve-fitting. Although

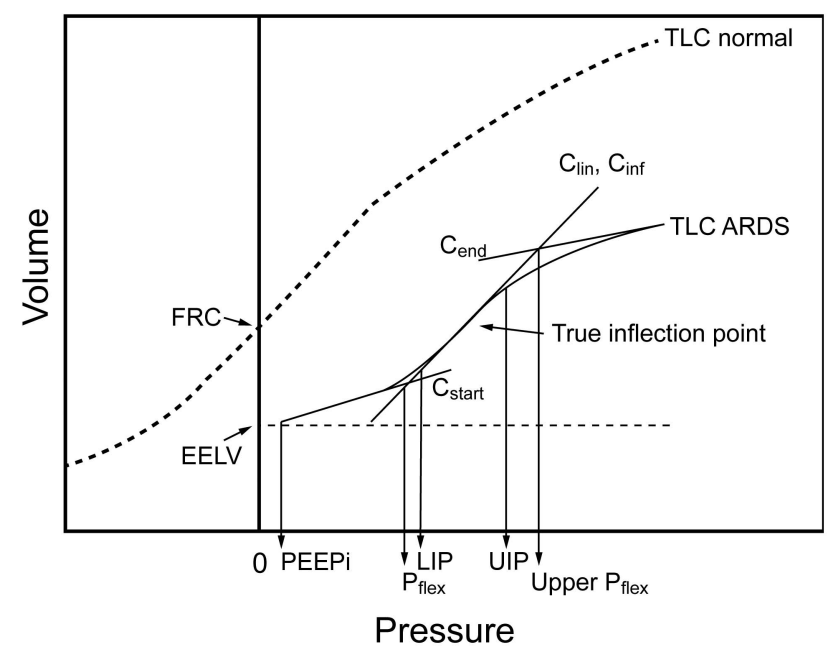

Fig. 19. Pressure-volume curve of a normal subject (dashed curve) and of a patient with ARDS (solid curve). The pressure-volume curve is shifted downwards on the volume axis and has a reduced total lung capacity (TLC). The sigmoid shape of the curve is much more evident in ARDS. Note the small amount of pressure at the start of the ARDS pressure-volume curve, indicating a small amount of intrinsic PEEP (PEEPi) at end-expiratory lung volume (EELV). Some investigators divide the curve into linear segments: $\mathrm{C}_{\text {start }}$, $\mathrm{C}_{\text {inf }}$ or $\mathrm{C}_{\text {lin }}$, and $\mathrm{C}_{\text {end }}$ (explained below). Using these segments, the upper and lower $\mathrm{P}_{\text {flex }}$ (the pressure at the intersection of 2 lines: a low compliance region at low lung volumes $\left[\mathrm{C}_{\text {start }}\right]$ and a higher compliance region at higher lung volumes $\left[\mathrm{C}_{\mathrm{inf}}\right]$ ) were defined by the intersection of these lines. The lower (LIP) and upper (UIP) inflection points are defined by where the curve first begins to deviate from the line $\mathrm{C}_{\text {lin }}$. Mathematically, these are not inflection points; the true inflection point (where concavity changes direction) is marked by the arrow. FRC = functional residual capacity. From Reference 47.

the inflation limb of the pressure-volume curve is most commonly measured, the deflation limb may be more useful for setting PEEP. Chest-wall mechanics potentially affect the shape of the P-V curve, necessitating $\mathrm{P}_{\mathrm{es}}$ measurement to separate lung from chest-wall effects. As with most measures of respiratory mechanics, the P-V curve treats the lungs as a single compartment, disregarding the inhomogeneity of the lungs of patients with ARDS.

Performing P-V curves and measuring lung volume corresponding to different PEEP levels can be used to assess PEEP-induced lung recruitment. ${ }^{53,54}$ Lung recruitment at a given airway pressure is observed as the difference in lung volume between P-V curves starting at different lung volumes corresponding to different levels of PEEP (Fig. 20).

\section{Flow-Volume Loops}

Flow-volume loops are displayed with flow as a function of volume. Some systems display expiratory flow in the positive direction, whereas other systems display expiratory flow in the negative direction. Analysis of the flow-volume loop may be helpful for identifying flow lim- 


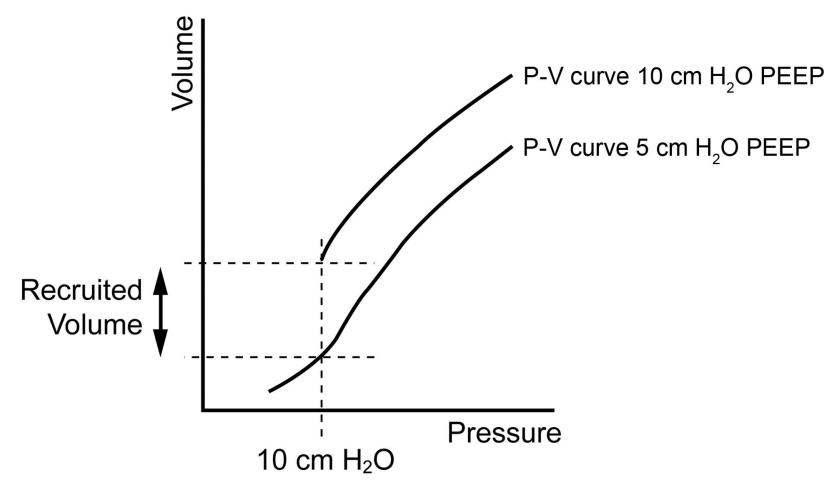

Fig. 20. Pressure-volume (P-V) curve technique to determine recruited lung volume with 2 levels of PEEP.

itation during expiration, the presence of secretions in the airway (Fig. 21), and bronchodilator response (Fig. 22)..$^{55}$ The flow-volume curve can provide an indication of excessive secretions more reliably than clinical examination, with the presence of excessive secretions in the airways producing a sawtooth pattern on both the inspiratory and expiratory flow-volume curves. ${ }^{56}$

\section{Tension-Time Index and Pressure-Time Product}

The tension-time index (TTI) has been used to predict diaphragmatic fatigue. It is calculated as: TTI $=\left(\mathrm{P}_{\mathrm{di}} / \mathrm{P}_{\mathrm{di}_{\max }}\right)$ $\times\left(\mathrm{T}_{\mathrm{I}} / \mathrm{T}_{\text {tot }}\right)$, where $\mathrm{P}_{\mathrm{di}_{\max }}$ is $\mathrm{P}_{\mathrm{di}}$ with maximum inhalation. ${ }^{57}$ $\mathrm{P}_{\mathrm{di}} / \mathrm{P}_{\mathrm{di}_{\max }}$ is the contractile force of the diaphragm, and $\mathrm{T}_{\mathrm{I}} / \mathrm{T}_{\text {tot }}$ is the contraction duration (duty cycle).

A tension-time index of $>0.15$ predicts respiratory muscle fatigue. Measurement of the $\mathrm{P}_{\mathrm{di}}$ requires esophageal and gastric pressure measurements, which are seldom performed in mechanically ventilated patients. A simpler form of the tension-time index is the pressure-time index (PTI), ${ }^{58}$ which can be determined more readily with equipment available in the ICU. It is calculated as: PTI $=$ $\left(\mathrm{P}_{\text {breath }} / \mathrm{P}_{\text {Imax }}\right) \times\left(\mathrm{T}_{\mathrm{I}} / \mathrm{T}_{\text {tot }}\right)$, where $\mathrm{P}_{\text {breath }}$ is the pressure required to generate a spontaneous breath, and $\mathrm{P}_{\mathrm{Imax}}$ is the maximum pressure that can be generated against an occluded airway. The $\mathrm{P}_{\text {breath }}$ can be determined with esophageal balloon measurements during a short trial of spontaneous breathing.

The pressure-time product (PTP) was developed to account for energy expenditures during the dynamic and isometric phases of respiration. ${ }^{59}$ WOB does not account for the isometric phase of respiration because there is no volume change. For example, energy is expended to overcome the threshold load of auto-PEEP, but technically this is not work because there is no volume moved into the lungs. Thus, different patients might have the same WOB, but the respiratory efficiency (WOB/oxygen consumption of respiratory muscles) could be quite different. The PTP is measured as the time integral of the difference between

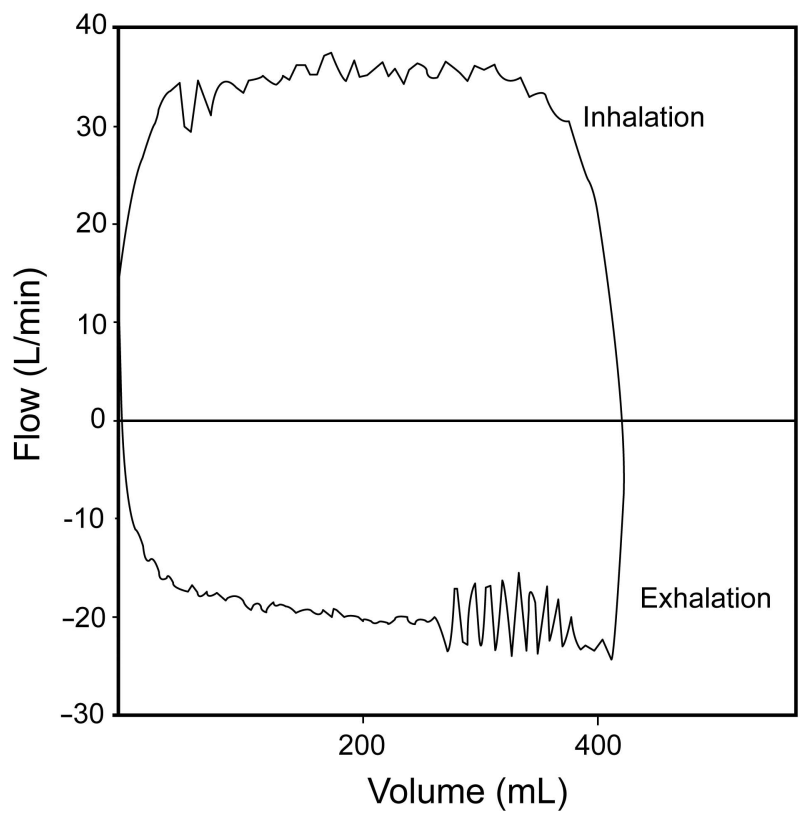

Fig. 21. Sawtooth pattern on flow-volume curve representing secretions in the airway.

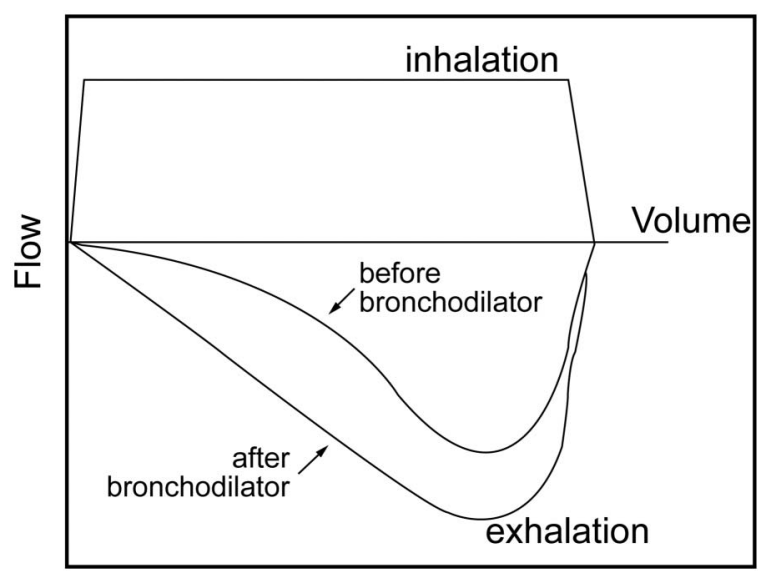

Fig. 22. Flow-volume curve illustrating response to bronchodilation in a patient with obstructive lung disease.

the $\mathrm{P}_{\mathrm{es}}$ tracing and the recoil pressure of the chest wall (Fig. 23). The traditional measurement of PTP may fail to account for the energy needed for active expiration, which has led to the determination of upper bound PTP and lower bound PTP to enable calculations of PTP throughout the respiratory cycle so that total energy expenditure can be approximated. ${ }^{60}$

\section{Esophageal Pressure for PEEP Titration}

Particularly in patients with extrapulmonary ARDS, ${ }^{61}$ the $\mathrm{C}_{\mathrm{CW}}$ may be reduced. This can result in an increase in $\mathrm{P}_{\mathrm{pl}}$, and if $\mathrm{P}_{\mathrm{pl}}$ is high relative to $\mathrm{P}_{\mathrm{alv}}$, there may be 

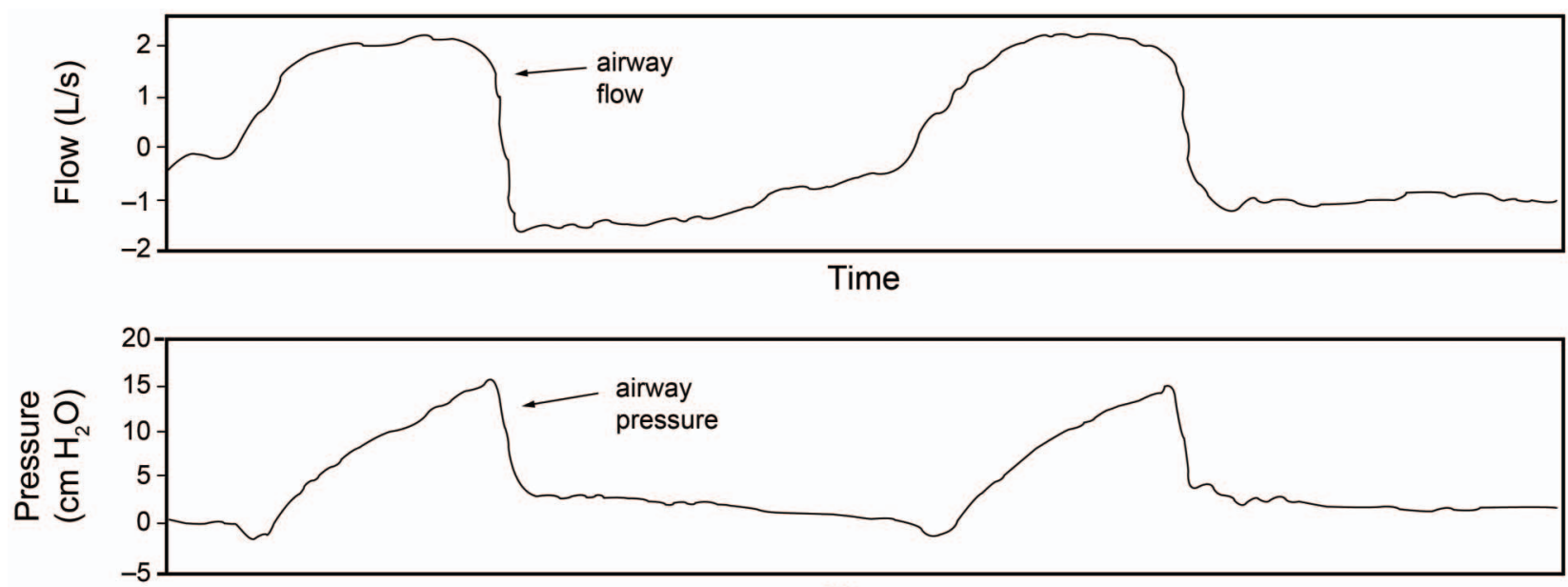

Time

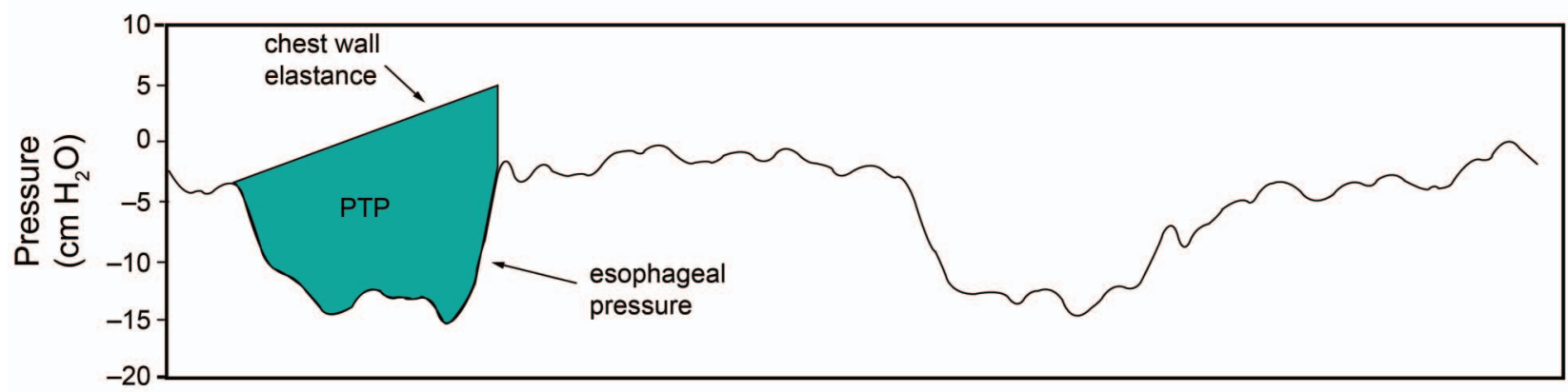

Time

Fig. 23. Illustration of the determination of pressure-time product (PTP). PTP is shown in the shaded area.

potential for alveolar collapse. In that case, it is desirable to set PEEP greater than $\mathrm{P}_{\mathrm{pl}}$. The use of an esophageal balloon to assess intra- $\mathrm{P}_{\mathrm{pl}}$ has been advocated to allow a more precise setting of PEEP (Figs. 24 and 25).

Talmor et al ${ }^{14}$ randomly assigned subjects with ARDS to PEEP adjusted according to measurements of $\mathrm{P}_{\mathrm{es}}$ or according to the ARDS Network low PEEP table. ${ }^{5}$ Compared with the PEEP table, the ventilatory strategy using $\mathrm{P}_{\mathrm{es}}$ to estimate the $\mathrm{P}_{\mathrm{L}}$ resulted in significantly greater oxygenation and compliance. There are several criticisms of this study. First, the primary end point was an improvement in oxygenation rather than a patientimportant outcome like mortality. Second, the low PEEP table of the ARDS Network is likely not sufficient in patients with moderate and severe ARDS. A multi-center trial is now underway using a more aggressive approach to PEEP in the control group (high PEEP table of the ARDS Network) ${ }^{62}$ and with a composite outcome of mortality and time off the ventilator at $28 \mathrm{~d}$ (ClinicalTrials.gov registration NCT01681225). Whether or not esophageal manometry proves useful for routine setting of PEEP, it is likely beneficial in selected patients, such as those with morbid obesity or abdominal compartment syndrome.

\section{Stress and Strain}

Stress is a force applied to an area, such as pressure applied to the lung parenchyma. Force applied at an angle generates shear stress. Strain is the physical deformation or change in shape of a structure, such as an alveolus, usually caused by stress. Elasticity is the reversible deformability of the alveolus generated by a stress, but allows the alveolus to return to its original shape. A stress that stretches the lungs may not seem to permanently change the size or shape of the lung, but it may affect lung integrity. The lungs are elastic structures that respond in an elastic manner to stress and strain.

$\mathrm{P}_{\mathrm{es}}$ can be used to assess stress and strain. ${ }^{63,64}$ The clinical equivalent of stress is $\mathrm{P}_{\mathrm{L}}$, and the clinical equivalent of strain is the ratio of $\Delta \mathrm{V}$ to the functional residual capacity (FRC): $\mathrm{P}_{\mathrm{L}}$ (stress) $=$ specific lung elastance $\times \Delta \mathrm{V} / \mathrm{FRC}$ (strain), where $\Delta \mathrm{V}$ is the change in lung volume above resting FRC with the addition of PEEP and $\mathrm{V}_{\mathrm{T}}$. Specific lung elastance is constant at $13.5 \mathrm{~cm} \mathrm{H}_{2} \mathrm{O}$. A harmful threshold of strain is $>2$. Thus, the harmful threshold of stress $\left(\mathrm{P}_{\mathrm{L}}\right)$ is $27 \mathrm{~cm} \mathrm{H}_{2} \mathrm{O}$. The recommended $\mathrm{P}_{\text {plat }}$ below $30 \mathrm{~cm} \mathrm{H}_{2} \mathrm{O}$ is therefore reasonable for most patients with ARDS. However, a higher $\mathrm{P}_{\text {plat }}$ may be safe when $\mathrm{P}_{\mathrm{L}}$ is reduced due to 


\section{A}
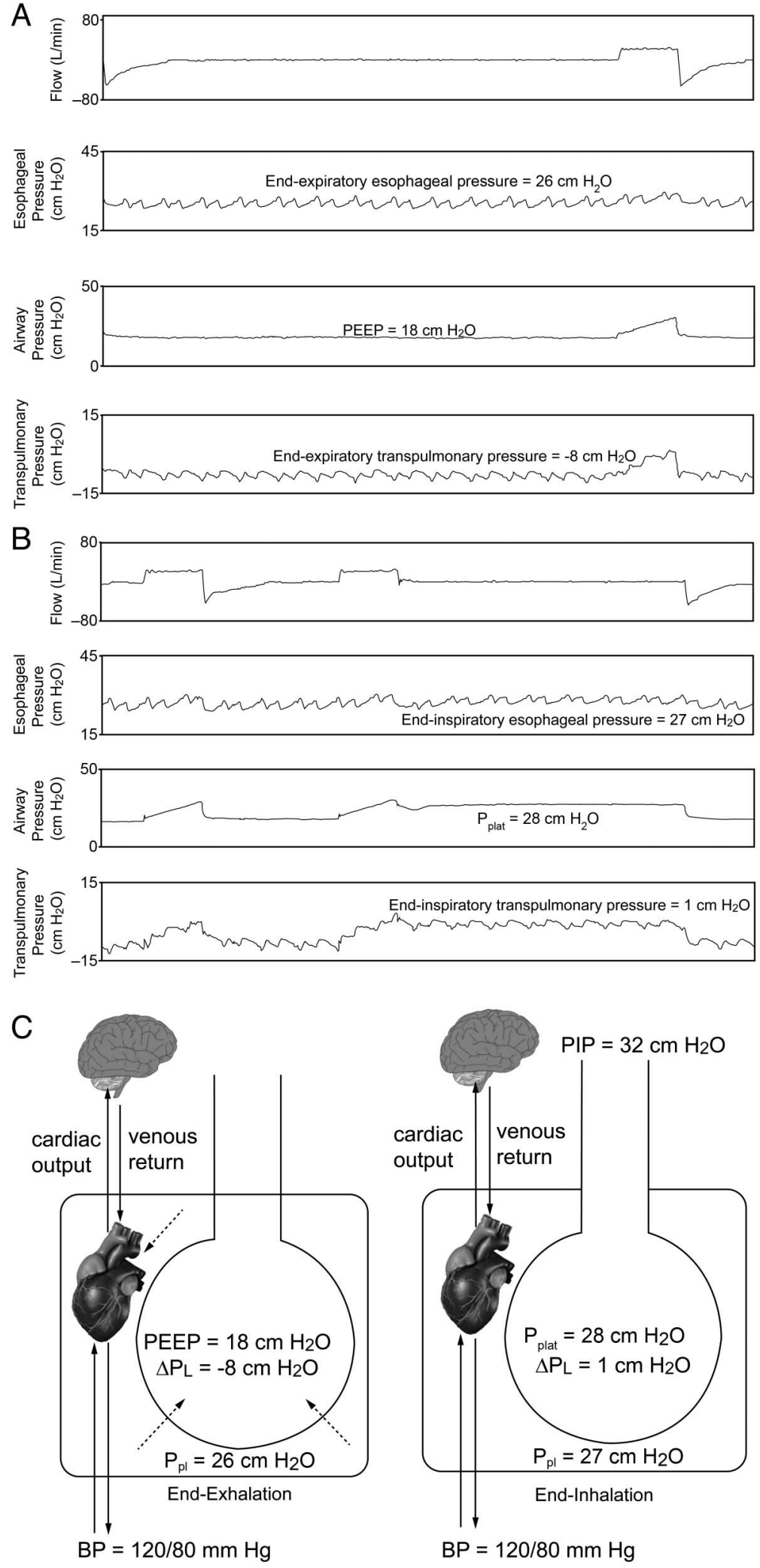

Fig. 24. Esophageal pressure, airway pressure, and transpulmonary pressure $\left(\mathrm{P}_{\mathrm{L}}\right)$ with PEEP set at $18 \mathrm{~cm} \mathrm{H}_{2} \mathrm{O}$. A: During expiratory pause. $\mathrm{B}$ : During inspiratory pause. C: As shown in the cartoon, there is a net collapsing pressure on the lungs, heart, and central circulation at the end of exhalation. At the mid-thoracic level (position of the esophageal balloon), the end-inspiratory $P_{L}$ is slightly positive. $P_{\text {plat }}=$ plateau pressure; PIP = peak inspiratory pressure; $\mathrm{P}_{\mathrm{pl}}=$ pleural pressure; $\mathrm{BP}=$ blood pressure. 
A
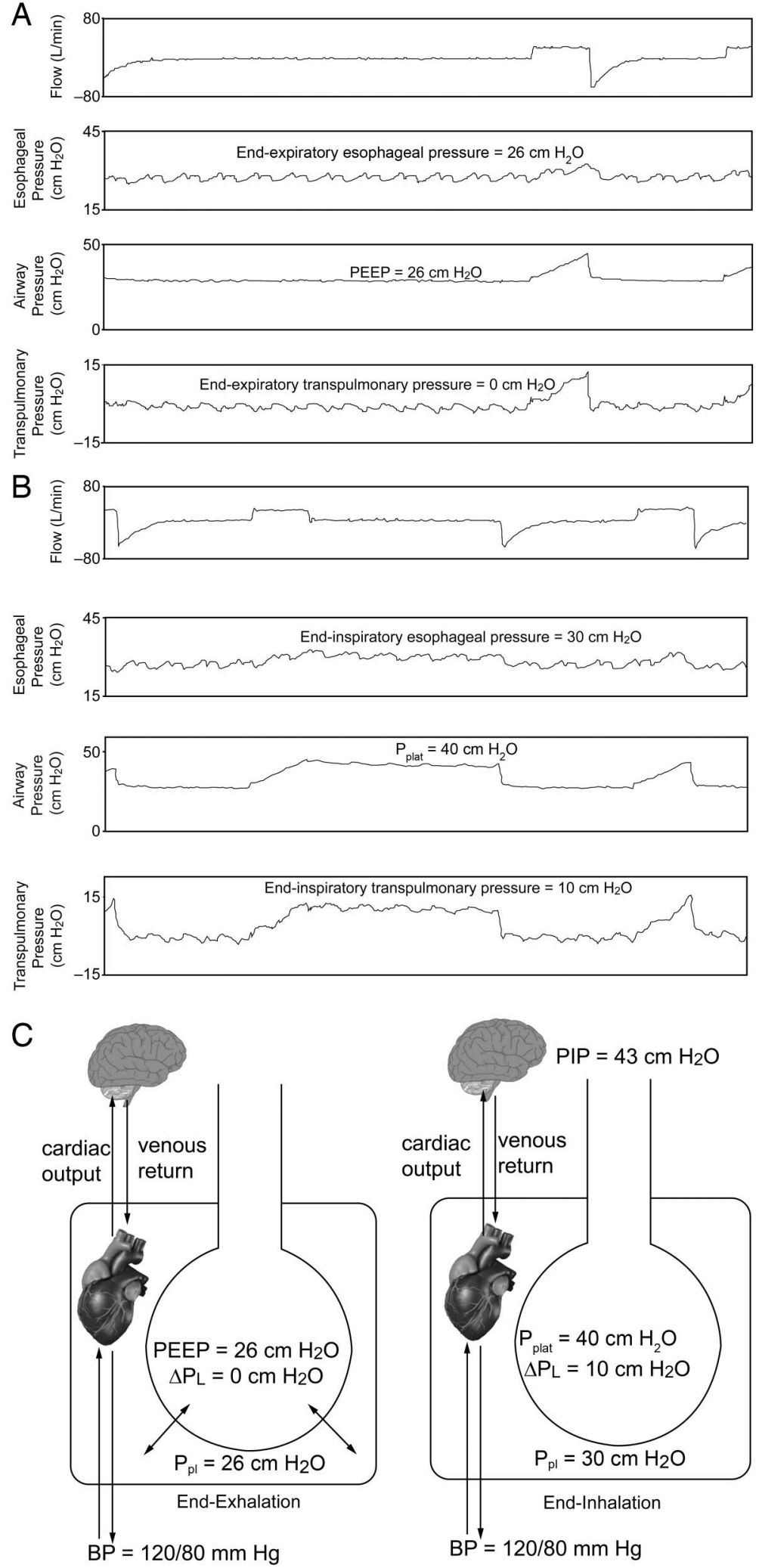

Fig. 25. Esophageal pressure, airway pressure, and transpulmonary pressure $\left(P_{L}\right)$ with PEEP set at $26 \mathrm{~cm} \mathrm{H}_{2} \mathrm{O}$ (same patient as Fig. 24). A: During expiratory pause. B: During inspiratory pause. C: as shown in the cartoon, the PEEP counterbalancs the $P_{\text {es }}\left(\right.$ (pleural pressure $\left.\left[P_{p l}\right]\right)$. Note that the same pressure is exerted on the heart and central circulation at the end of exhalation. At the mid-thoracic level (position of the esophageal balloon), the end-inspiratory $\mathrm{P}_{\mathrm{L}}$ is $10 \mathrm{~cm} \mathrm{H}_{2} \mathrm{O}$, which is likely safe, despite a plateau pressure $\left(\mathrm{P}_{\text {plat }}\right)$ of $40 \mathrm{~cm} \mathrm{H}_{2} \mathrm{O}$. Note that blood pressure (BP) is not affected because there is no increase in $\mathrm{P}_{\mathrm{pl}}$ with the addition of PEEP. PIP = peak inspiratory pressure; $\mathrm{Ppl}=$ pleural pressure; $\mathrm{BP}=$ blood pressure. 
an increase in $\mathrm{P}_{\mathrm{pl}}$. This makes a case for measurement of $\mathrm{P}_{\mathrm{es}}$ in a patient with a stiff chest wall.

It is also possible to measure strain and then calculate stress if the end-expiratory lung volume is measured as FRC. However, strain is the lung volume above resting FRC without PEEP. Thus, end-expiratory lung volume is measured without PEEP to determine strain, which might not be safe, particularly in patients with severe ARDS.

This concept is illustrated in Figure 25. When the PEEP is set at $26 \mathrm{~cm} \mathrm{H}_{2} \mathrm{O}$, the end-inspiratory $\mathrm{P}_{\mathrm{L}}$ (stress) is $10 \mathrm{~cm} \mathrm{H}_{2} \mathrm{O}$, and strain is 0.74. In this case, stress at $10 \mathrm{~cm} \mathrm{H}_{2} \mathrm{O}$ and strain at 0.74 are both safe, despite a $\mathrm{P}_{\text {plat }}$ of $40 \mathrm{~cm} \mathrm{H}_{2} \mathrm{O}$.

Stress will be concentrated in the setting of inhomogeneity within the lungs where regions of collapse border regions of ventilation. This is called a stress raiser ${ }^{64}$ and was first described many years ago by Mead et al. ${ }^{65}$ They considered 2 adjacent lung regions fully expanded at a $\mathrm{P}_{\mathrm{L}}$ of $30 \mathrm{~cm} \mathrm{H}_{2} \mathrm{O}$. If one of the 2 regions loses elasticity (ie, consolidation or collapse), the applied force concentrates in the other, thereby increasing its strain and stress. Mead et al ${ }^{65}$ calculated that, if the volume ratio of the 2 regions goes from 10/10 (both regions distended) to 10/1 (one region distended and the other collapsed/consolidated), the stress of the open regions increases from 30 to $130 \mathrm{~cm} \mathrm{H}_{2} \mathrm{O}$. The mathematical basis of this computation relies on the fact that the stress is a force/area ratio. A volume ratio of $10 / 1$ should be transformed into a ratio of areas. As area is volume to a power of 0.66 , a volume ratio of $10 / 1$ is equal to an area ratio of $(10 / 1)^{0.66}$, which is 4.57 . Therefore, the initial force applied to the 2 lung regions should be multiplied almost 5-fold, thus increasing the stress of the open unit to $30 \times 4.57 \mathrm{~cm} \mathrm{H}_{2} \mathrm{O}=137 \mathrm{~cm} \mathrm{H}_{2} \mathrm{O}$. The basic concept is that in an inhomogeneous lung, which is usually the case in mechanically ventilated patients, the presence of these areas of stress raisers might create dangerous regional $\mathrm{P}_{\mathrm{L}}$ despite an acceptable $\mathrm{P}_{\text {plat }}$ and $\mathrm{P}_{\mathrm{L}}$. This effect can be minimized clinically by using the lowest $P_{\text {plat }}$ possible for an individual patient.

\section{Spontaneous Breathing and Pressure-Targeted Ventilation}

Many years ago, Dreyfuss and Saumon ${ }^{66}$ conducted some interesting studies related to ventilator-induced lung injury. They subjected rats to low or high $\mathrm{V}_{\mathrm{T}}$ ventilation, using identical airway pressure $\left(45 \mathrm{~cm} \mathrm{H}_{2} \mathrm{O}\right)$ in both groups. Low $\mathrm{V}_{\mathrm{T}}$ with high airway pressure was produced by thoracoabdominal strapping during positive airway pressure ventilation. The rats subjected to high $\mathrm{V}_{\mathrm{T}}$ and high airway pressure ventilation quickly developed ventilator-induced lung injury. However, the animals that underwent thoracoabdominal strapping and were ventilated with high airway pressure but a normal $\mathrm{V}_{\mathrm{T}}$ did not develop ventilator-induced lung injury. The lungs of the animals with decreased $\mathrm{C}_{\mathrm{CW}}$ were

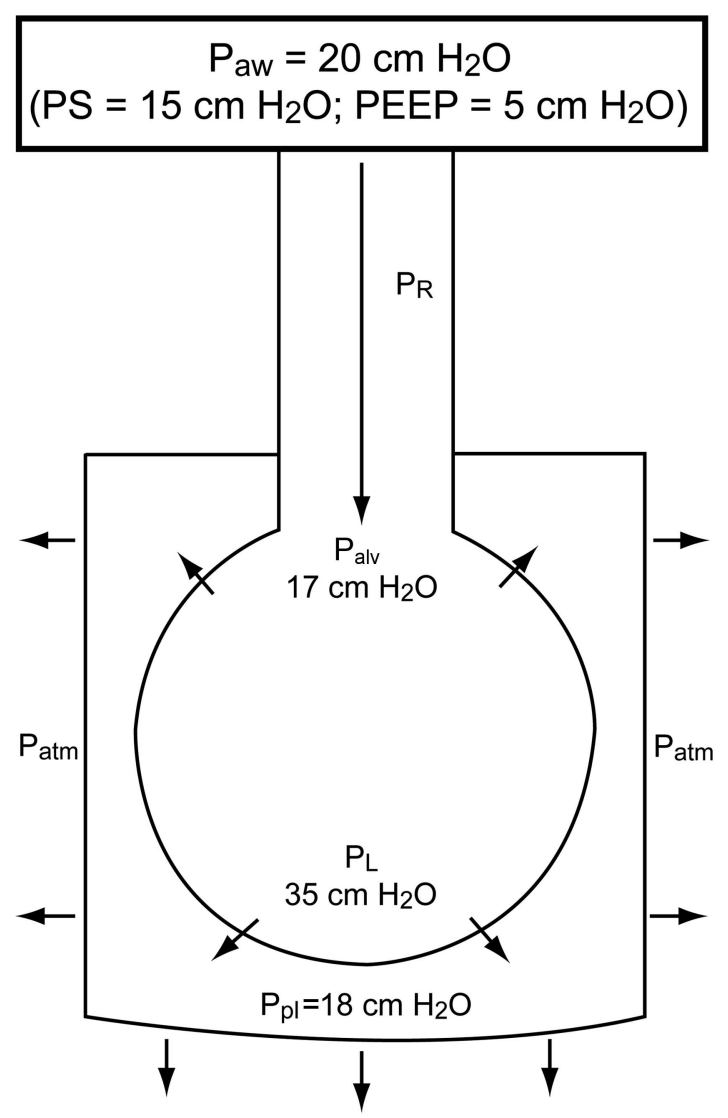

Fig. 26. Cartoon illustrating how a strong inspiratory effort can result in a high transpulmonary pressure $\left(P_{\mathrm{L}}\right)$. $\mathrm{P}_{\text {aw }}=$ airway pressure; $P S=$ pressure support; $P_{R}=$ pressure drop due to airway resistance; $\mathrm{P}_{\text {alv }}=$ alveolar pressure; $\mathrm{P}_{\mathrm{atm}}=$ atmospheric pressure; $\mathrm{P}_{\mathrm{pl}}=$ pleural pressure.

presumably subjected to less stress. Another group of rats received negative-pressure ventilation with high $\mathrm{V}_{\mathrm{T}}$, and these animals developed ventilator-induced lung injury.

More recently, Yoshida et al ${ }^{67}$ evaluated spontaneous breathing and muscle paralysis in 2 different severities of experimental lung injury. They found that in rabbits with mild lung injury, spontaneous breathing was beneficial to lung recruitment. However, in animals with severe lung injury, spontaneous breathing worsened lung injury, suggesting that muscle paralysis might be more protective for injured lungs by preventing injuriously high $\mathrm{P}_{\mathrm{L}}$. In another experimental study, Yoshida et al ${ }^{68}$ found that spontaneous breathing caused pendelluft during early inflation, which was associated with more negative local $\mathrm{P}_{\mathrm{pl}}$ in dependent lung regions versus non-dependent regions. This occurred despite limitation of $\mathrm{V}_{\mathrm{T}}$ to $<6 \mathrm{~mL} / \mathrm{kg}$. Comparable inflation of dependent lung during paralysis required almost 3-fold greater driving pressure (and $\mathrm{V}_{\mathrm{T}}$ ) versus spontaneous breathing. These data suggest that spontaneous breathing might be harmful in the setting of moderate-to-severe lung injury. Indeed, several case reports have described barotrauma in spontaneously breath- 

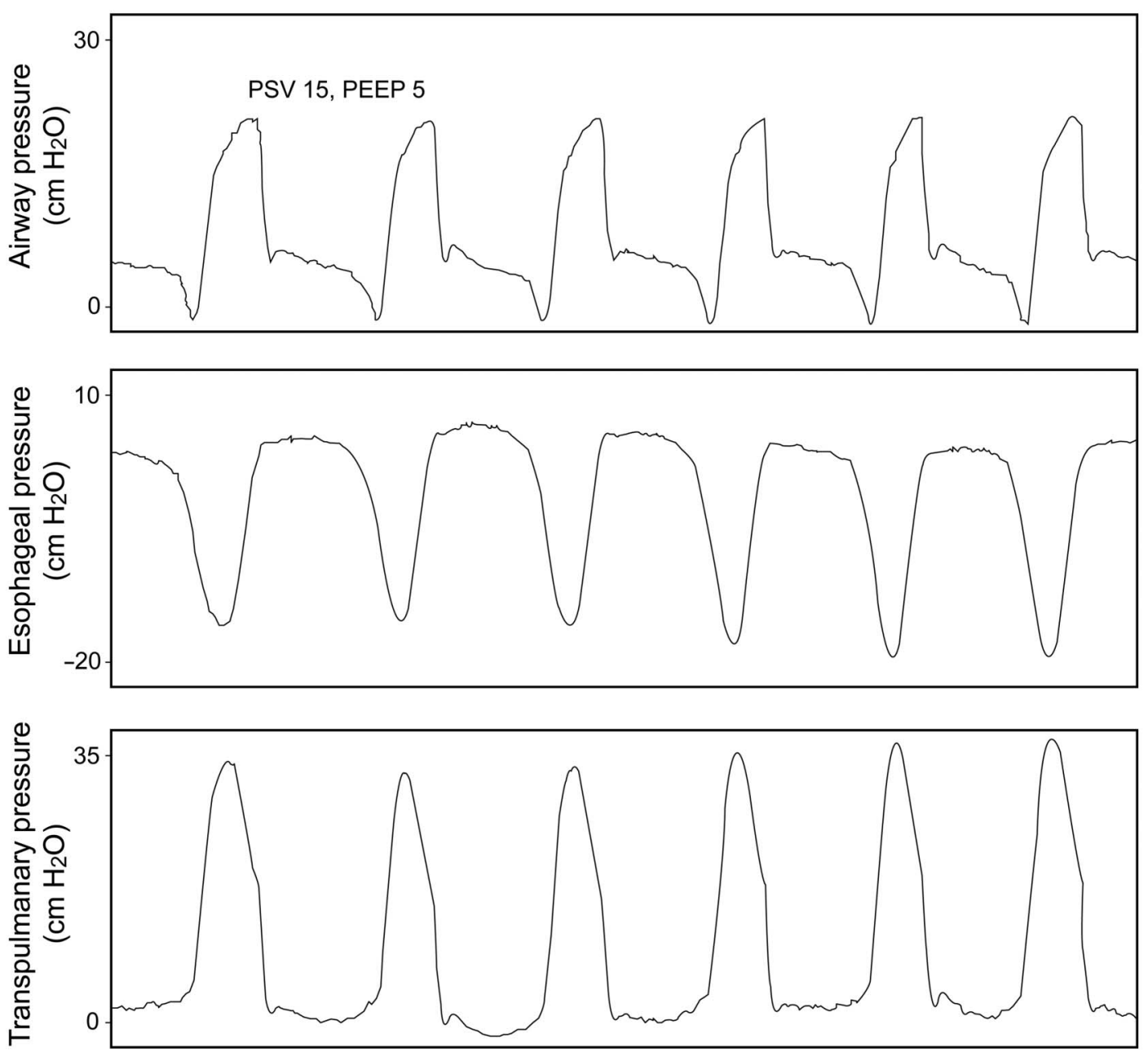

Fig. 27. Airway pressure, esophageal pressure, and transpulmonary pressure $\left(P_{L}\right)$ for a patient on pressure support ventilation (PSV). Note the high $P_{L}$ due to the patient's strong inspiratory effort.

ing patients receiving pressure support ventilation or airway pressure release ventilation. ${ }^{69,70}$

The potential benefits of pressure-targeted modes are better enhanced patient-ventilator interaction, the possibility of less sedation, improved ability to participate in care such as mobilization and ambulation, and better ventilation of dorsal lung units with subsequently improved alveolar recruitment and arterial oxygenation. However, these possible benefits must be weighed against the potential for alveolar over-distention with spontaneous breathing efforts. Imagine a patient who is being ventilated with a pressure-targeted mode such as pressure control, pressure support, or airway pressure release ventilation. The ventilator will provide flow to maintain constant airway pressure, and the spontaneous breathing efforts of the patient will lower the $\mathrm{P}_{\mathrm{p}}$, thus increasing $\mathrm{P}_{\mathrm{L}}$. As illustrated in Figures 26 and 27, a potentially injurious $P_{L}$ can occur using an airway pressure that might otherwise be considered safe.
Respiratory variation in central venous pressure, which is commonly available in mechanically ventilated patients, can provide information about $\mathrm{P}_{\mathrm{pl}}$ changes during the respiratory cycle. Large negative-pressure swings in central venous pressure during spontaneous breathing suggest a high $\mathrm{P}_{\mathrm{L}}$. Perhaps most important, and easiest to monitor at the bedside, is the $\mathrm{V}_{\mathrm{T}}$ that results from the patient's inspiratory effort. If the $\mathrm{V}_{\mathrm{T}}$ is not excessive, in most cases, the $\mathrm{P}_{\mathrm{L}}$ will be acceptable. However, due to the inhomogeneity of the disease process, a high $\mathrm{P}_{\mathrm{L}}$ might result in regional over-distention despite an acceptable $\mathrm{V}_{\mathrm{T}}$. Regardless of the ventilator mode, in critically ill patients, the $\mathrm{V}_{\mathrm{T}}$ target should be $6 \mathrm{~mL} / \mathrm{kg}$ of ideal body weight.

\section{Pleural Pressure and Hemodynamics During Mechanical Ventilation}

A common clinical question relates to the effect of positive-pressure ventilation on $\mathrm{P}_{\mathrm{pl}}$. $\mathrm{P}_{\mathrm{pl}}$ is independent of 


\section{Respiratory Mechanics During Mechanical Ventilation}

$\mathrm{C}_{\mathrm{L}}{ }^{17}: \mathrm{P}_{\mathrm{pl}}=$ lung volume/ $\mathrm{C}_{\mathrm{CW}}$. Thus, it is not correct to refer to the amount of pressure transmitted to the pleural space because $\mathrm{P}_{\mathrm{pl}}$ is determined by lung volume $\left(\mathrm{V}_{\mathrm{T}}\right.$ and PEEP) and $\mathrm{C}_{\mathrm{CW}} \cdot \mathrm{P}_{\mathrm{pl}}$ as a fraction of $\mathrm{P}_{\mathrm{alv}}$ is determined by the relationship: $\Delta \mathrm{P}_{\mathrm{pl}} / \Delta \mathrm{P}_{\mathrm{alv}}=\mathrm{C}_{\mathrm{L}} /\left(\mathrm{C}_{\mathrm{L}}+\mathrm{C}_{\mathrm{CW}}\right)$, or $\Delta \mathrm{P}_{\mathrm{pl}} / \Delta \mathrm{P}_{\text {alv }}=\mathrm{C}_{\mathrm{RS}} / \mathrm{C}_{\mathrm{CW}}$. Under normal conditions, where $\mathrm{C}_{\mathrm{L}}$ and $\mathrm{C}_{\mathrm{CW}}$ are equal, $\Delta \mathrm{P}_{\mathrm{pl}}$ will be half of $\Delta \mathrm{P}_{\text {alv }}$. When $\mathrm{C}_{\mathrm{CW}}$ is reduced relative to $\mathrm{C}_{\mathrm{L}}, \Delta \mathrm{P}_{\mathrm{pl}}$ will be a greater fraction of $\Delta \mathrm{P}_{\text {alv }}$. On the other hand, when $\mathrm{C}_{\mathrm{L}}$ is reduced relative to $\mathrm{C}_{\mathrm{CW}}, \Delta \mathrm{P}_{\mathrm{pl}}$ will be a lower fraction of $\Delta \mathrm{P}_{\text {alv }}$.

$\mathrm{P}_{\mathrm{pl}}$ affects hemodynamics due to its effect on the heart and central circulation. When $\mathrm{P}_{\mathrm{pl}}$ is increased due to a decreased $\mathrm{C}_{\mathrm{CW}}$, use of PEEP that counterbalances the collapsing effect of the chest wall should not compromise hemodynamics until the PEEP exceeds the $\mathrm{P}_{\mathrm{pl}}$ due to chest-wall effects. Sarge et $\mathrm{al}^{71}$ reported that in subjects with ARDS, individualizing PEEP to optimize $\mathrm{P}_{\mathrm{L}}$ using esophageal manometry does not compromise hemodynamic function.

\section{Summary}

A variety of respiratory mechanics can be assessed in mechanically ventilated patients. This can be useful as a probe of the underlying pathophysiology. Assessment of respiratory mechanics can also be used to set the ventilator to minimize lung injury.

\section{REFERENCES}

1. Hess DR, Medoff BD, Fessler MB. Pulmonary mechanics and graphics during positive pressure ventilation. Int Anesthesiol Clin 1999; 37(3):15-34.

2. Lucangelo U, Bernabé $F$, Blanch L. Lung mechanics at the bedside: make it simple. Curr Opin Crit Care 2007;13(1):64-72.

3. Sanborn WG. Monitoring respiratory mechanics during mechanical ventilation: where do the signals come from? Respir Care 2005; 50(1):28-52; discussion 52-54

4. Lucangelo U, Bernabé F, Blanch L. Respiratory mechanics derived from signals in the ventilator circuit. Respir Care 2005;50(1):55-65; discussion 65-57.

5. Ventilation with lower tidal volumes as compared with traditional tidal volumes for acute lung injury and the acute respiratory distress syndrome. The Acute Respiratory Distress Syndrome Network. N Engl J Med 2000;342(18):1301-1308.

6. Terragni PP, Filippini C, Slutsky AS, Birocco A, Tenaglia T, Grasso $S$, et al. Accuracy of plateau pressure and stress index to identify injurious ventilation in patients with acute respiratory distress syndrome. Anesthesiology 2013;119(4):880-889.

7. Terragni PP, Rosboch G, Tealdi A, Corno E, Menaldo E, Davini O, et al. Tidal hyperinflation during low tidal volume ventilation in acute respiratory distress syndrome. Am J Respir Crit Care Med 2007;175(2):160-166.

8. Al-Rawas N, Banner MJ, Euliano NR, Tams CG, Brown J, Martin $\mathrm{AD}$, Gabrielli A. Expiratory time constant for determinations of plateau pressure, respiratory system compliance, and total resistance. Crit Care 2013;17(1):R23.

9. Marini JJ. Dynamic hyperinflation and auto-positive end-expiratory pressure: lessons learned over 30 years. Am J Respir Crit Care Med 2011;184(7):756-762.

10. Blanch L, Bernabé F, Lucangelo U. Measurement of air trapping, intrinsic positive end-expiratory pressure, and dynamic hyperinfla- tion in mechanically ventilated patients. Respir Care 2005;50(1): 110-123; discussion 123-124.

11. Benditt JO. Esophageal and gastric pressure measurements. Respir Care 2005;50(1):68-75; discussion 75-77.

12. Talmor DS, Fessler HE. Are esophageal pressure measurements important in clinical decision-making in mechanically ventilated patients? Respir Care 2010;55(2):162-172; discussion 172-174.

13. Talmor D, Sarge T, O’Donnell CR, Ritz R, Malhotra A, Lisbon A, Loring SH. Esophageal and transpulmonary pressures in acute respiratory failure. Crit Care Med 2006;34(5):1389-1394.

14. Talmor D, Sarge T, Malhotra A, O'Donnell CR, Ritz R, Lisbon A, et al. Mechanical ventilation guided by esophageal pressure in acute lung injury. N Engl J Med 2008;359(20):2095-2104.

15. Sarge T, Talmor D. Targeting transpulmonary pressure to prevent ventilator induced lung injury. Minerva Anestesiol 2009;75(5):293-299.

16. Loring SH, O’Donnell CR, Behazin N, Malhotra A, Sarge T, Ritz R, et al. Esophageal pressures in acute lung injury: do they represent artifact or useful information about transpulmonary pressure, chest wall mechanics, and lung stress? J Appl Physiol 2010;108(3):515-522.

17. Hess DR, Bigatello LM. The chest wall in acute lung injury/acute respiratory distress syndrome. Curr Opin Crit Care 2008;14(1):94-102.

18. Akoumianaki E, Maggiore SM, Valenza F, Bellani G, Jubran A, Loring $\mathrm{SH}$, et al. The application of esophageal pressure measurement in patients with respiratory failure. Am J Respir Crit Care Med 2014;189(5):520-531.

19. Piraino T, Cook DJ. Optimal PEEP guided by esophageal balloon manometry. Respir Care 2011;56(4):510-513.

20. Hager DN, Brower RG. Customizing lung-protective mechanical ventilation strategies. Crit Care Med 2006;34(5):1554-1555.

21. Guérin C, Richard JC. Comparison of 2 correction methods for absolute values of esophageal pressure in subjects with acute hypoxemic respiratory failure, mechanically ventilated in the ICU. Respir Care 2012;57(12):2045-2051.

22. Malbrain ML, Deeren D, De Potter TJ. Intra-abdominal hypertension in the critically ill: it is time to pay attention. Curr Opin Crit Care 2005;11(2):156-171.

23. Sindi A, Piraino T, Alhazzani W, Tunks M, Faden M, Ma J, et al. The correlation between esophageal and abdominal pressures in mechanically ventilated patients undergoing laparoscopic surgery. Respir Care 2014;59(4):491-496.

24. Malbrain ML. Different techniques to measure intra-abdominal pressure (IAP): time for a critical re-appraisal. Intensive Care Med 2004; 30(3):357-371.

25. Ranieri VM, Brienza N, Santostasi S, Puntillo F, Mascia L, Vitale N, et al. Impairment of lung and chest wall mechanics in patients with acute respiratory distress syndrome: role of abdominal distension. Am J Respir Crit Care Med 1997;156(4 Pt 1):1082-1091.

26. Cheatham ML, De Waele JJ, De Laet I, De Keulenaer B, Widder S, Kirkpatrick AW, et al. The impact of body position on intraabdominal pressure measurement: A multicenter analysis. Crit Care Med 2009;37(7):2187-2190.

27. Sharshar T, Desmarais G, Louis B, Macadou G, Porcher R, Harf A, et al. Transdiaphragmatic pressure control of airway pressure support in healthy subjects. Am J Respir Crit Care Med 2003;168(7):760-769.

28. Lecamwasam HS, Hess D, Brown R, Kwolek CJ, Bigatello LM. Diaphragmatic paralysis after endovascular stent grafting of a thoracoabdominal aortic aneurysm. Anesthesiology 2005;102(3):690-692.

29. Nilsestuen JO, Hargett KD. Using ventilator graphics to identify patient-ventilator asynchrony. Respir Care 2005;50(2):202-234; discussion 232-234.

30. Grasso S, Stripoli T, De Michele M, Bruno F, Moschetta M, Angelelli $\mathrm{G}$, et al. ARDSnet ventilatory protocol and alveolar hyperinflation: role of positive end-expiratory pressure. Am J Respir Crit Care Med 2007;176(8):761-767. 


\section{Respiratory Mechanics During Mechanical Ventilation}

31. Hess DR. Approaches to conventional mechanical ventilation of the patient with acute respiratory distress syndrome. Respir Care 2011; 56(10):1555-1572.

32. Brunner JX, Laubscher TP, Banner MJ, Iotti G, Braschi A. Simple method to measure total expiratory time constant based on the passive expiratory flow-volume curve. Crit Care Med 1995;23(6):1117-1122.

33. Ninane V, Leduc D, Kafi SA, Nasser M, Houa M, Sergysels R. Detection of expiratory flow limitation by manual compression of the abdominal wall. Am J Respir Crit Care Med 2001;163(6):1326-1330.

34. Bolzan DW, Gomes WJ, Faresin SM, de Camargo Carvalho AC, De Paola AA, Guizilini S. Volume-time curve: an alternative for endotracheal tube cuff management. Respir Care 2012;57(12):2039-2044.

35. Branson RD, Johannigman JA. Innovations in mechanical ventilation. Respir Care 2009;54(7):933-947.

36. Owens RL, Stigler WS, Hess DR. Do newer monitors of exhaled gases, mechanics, and esophageal pressure add value? Clin Chest Med 2008;29(2):297-312, vi-vii.

37. Suter PM, Fairley B, Isenberg MD. Optimum end-expiratory airway pressure in patients with acute pulmonary failure. N Engl J Med 1975;292(6):284-289.

38. Mercat A, Richard JC, Vielle B, Jaber S, Osman D, Diehl JL, et al. Positive end-expiratory pressure setting in adults with acute lung injury and acute respiratory distress syndrome: a randomized controlled trial. JAMA 2008;299(6):646-655.

39. Pintado MC, de Pablo R, Trascasa M, Milicua JM, Rogero S, Daguerre $\mathrm{M}$, et al. Individualized PEEP setting in subjects with ARDS: a randomized controlled pilot study. Respir Care 2013;58(9):1416-1423.

40. Hess D, Tabor T. Comparison of six methods to calculate airway resistance during mechanical ventilation in adults. J Clin Monit 1993; 9(4):275-282

41. Banner MJ, Jaeger MJ, Kirby RR. Components of the work of breathing and implications for monitoring ventilator-dependent patients. Crit Care Med 1994;22(3):515-523.

42. Banner MJ, Euliano NR, Brennan V, Peters C, Layon AJ, Gabrielli A. Power of breathing determined noninvasively with use of an artificial neural network in patients with respiratory failure. Crit Care Med 2006;34(4):1052-1059.

43. Banner MJ, Euliano NR, Martin AD, Al-Rawas N, Layon AJ, Gabrielli A. Noninvasive work of breathing improves prediction of post-extubation outcome. Intensive Care Med 2012;38(2):248-255.

44. Bonett S, Banner MJ, Euliano NR, Peters CW, Layon AJ, Gabrielli A. Pressure support ventilation advisory system provides valid recommendations for setting ventilator. Respir Care 2011;56(3):271-277.

45. Idris AH, Convertino VA, Ratliff DA, Doerr DF, Lurie KG, Gabrielli A, Banner MJ. Imposed power of breathing associated with use of an impedance threshold device. Respir Care 2007;52(2):177-183.

46. Ozcan MS, Bonett SW, Martin AD, Gabrielli A, Layon AJ, Banner MJ. Abnormally increased power of breathing as a complication of closed endotracheal suction catheter systems. Respir Care 2006;51(4):423-425.

47. Branson RD. Modes to facilitate ventilator weaning. Respir Care 2012;57(10):1635-1648.

48. Harris RS. Pressure-volume curves of the respiratory system. Respir Care 2005;50(1):78-98; discussion 98-99.

49. Villar J, Kacmarek RM, Pérez-Méndez L, Aguirre-Jaime A. A high positive end-expiratory pressure, low tidal volume ventilatory strategy improves outcome in persistent acute respiratory distress syndrome: a randomized, controlled trial. Crit Care Med 2006;34(5):1311-1318.

50. Amato MB, Barbas CS, Medeiros DM, Magaldi RB, Schettino GP, Lorenzi-Filho G, et al. Effect of a protective-ventilation strategy on mortality in the acute respiratory distress syndrome. N Engl J Med 1998;338(6):347-354.

51. Owens RL, Hess DR, Malhotra A, Venegas JG, Harris RS. Effect of the chest wall on pressure-volume curve analysis of acute respiratory distress syndrome lungs. Crit Care Med 2008;36(11):2980-2985.
52. Harris RS, Hess DR, Venegas JG. An objective analysis of the pressure-volume curve in the acute respiratory distress syndrome. Am J Respir Crit Care Med 2000;161(2 Pt 1):432-439.

53. Blanch L, López-Aguilar J, Villagrá A. Bedside evaluation of pressure-volume curves in patients with acute respiratory distress syndrome. Curr Opin Crit Care 2007;13(3):332-337.

54. Albaiceta GM, Blanch L, Lucangelo U. Static pressure-volume curves of the respiratory system: were they just a passing fad? Curr Opin Crit Care 2008;14(1):80-86.

55. Dhand R. Ventilator graphics and respiratory mechanics in the patient with obstructive lung disease. Respir Care 2005;50(2):246-261; discussion 259-261.

56. Jubran A, Tobin MJ. Use of flow-volume curves in detecting secretions in ventilator-dependent patients. Am J Respir Crit Care Med 1994;150(3):766-769.

57. Stoller JK. Physiologic rationale for resting the ventilatory muscles. Respir Care 1991;36(4):290-296.

58. Jabour ER, Rabil DM, Truwit JD, Rochester DF. Evaluation of a new weaning index based on ventilatory endurance and the efficiency of gas exchange. Am Rev Respir Dis 1991;144(3 Pt 1):531-537.

59. Grinnan DC, Truwit JD. Clinical review: respiratory mechanics in spontaneous and assisted ventilation. Crit Care 2005;9(5):472-484.

60. Jubran A, Van de Graaff WB, Tobin MJ. Variability of patientventilator interaction with pressure support ventilation in patients with chronic obstructive pulmonary disease. Am J Respir Crit Care Med 1995;152(1):129-136.

61. Gattinoni L, Pelosi P, Suter PM, Pedoto A, Vercesi P, Lissoni A. Acute respiratory distress syndrome caused by pulmonary and extrapulmonary disease. Different syndromes? Am J Respir Crit Care Med 1998;158(1):3-11

62. Brower RG, Lanken PN, MacIntyre N, Matthay MA, Morris A, Ancukiewicz M, et al. Higher versus lower positive end-expiratory pressures in patients with the acute respiratory distress syndrome. N Engl J Med 2004;351(4):327-336.

63. Chiumello D, Carlesso E, Cadringher P, Caironi P, Valenza F, Polli $F$, et al. Lung stress and strain during mechanical ventilation for acute respiratory distress syndrome. Am J Respir Crit Care Med 2008;178(4):346-355.

64. Gattinoni L, Carlesso E, Caironi P. Stress and strain within the lung. Curr Opin Crit Care 2012;18(1):42-47.

65. Mead J, Takishima T, Leith D. Stress distribution in lungs: a model of pulmonary elasticity. J Appl Physiol 1970;28(5):596-608.

66. Dreyfuss D, Saumon G. Ventilator-induced lung injury: lessons from experimental studies. Am J Respir Crit Care Med 1998;157(1):294-323.

67. Yoshida T, Uchiyama A, Matsuura N, Mashimo T, Fujino Y. The comparison of spontaneous breathing and muscle paralysis in two different severities of experimental lung injury. Crit Care Med 2013;41(2): 536-545.

68. Yoshida T, Torsani V, Gomes S, De Santis RR, Beraldo MA, Costa EL, et al. Spontaneous effort causes occult pendelluft during mechanical ventilation. Am J Respir Crit Care Med 2013;188(12):1420-1427.

69. Leray V, Bourdin G, Flandreau G, Bayle F, Wallet F, Richard JC, Guérin C. A case of pneumomediastinum in a patient with acute respiratory distress syndrome on pressure support ventilation. Respir Care 2010;55(6):770-773.

70. Sasidhar M, Chatburn RL. Tidal volume variability during airway pressure release ventilation: case summary and theoretical analysis. Respir Care 2012;57(8):1325-1333.

71. Sarge T, Loring SH, Yitsak-Sade M, Malhotra A, Novack V, Talmor D. Raising positive end-expiratory pressures in ARDS to achieve a positive transpulmonary pressure does not cause hemodynamic compromise. Intensive Care Med 2014;40(1):126-128. 